\title{
Brain-targeted dual site-selective functionalized poly(beta-amino esters) delivery platform for nerve regeneration
}

Luzhong Zhang, $\dagger^{*} \perp$ Ke Yao, $\dagger \perp$ Yuqing Wang, $\dagger$ You Lang Zhou, + Zexi Fu, $\dagger$

Guicai Li, $†$ Jue Ling, $†$ Yumin Yang ${ }^{* *}$

$\dagger$ Key Laboratory of Neuroregeneration of Jiangsu and Ministry of Education, Coinnovation Center of Neuroregeneration, Nantong University, 226001, Nantong, PR China

$\ddagger$ Hand Surgery Research Center, Research Center of Clinical Medicine, Affiliated Hospital of Nantong University, 226001, Nantong, PR China

$\perp$ K. Y. and L. Z. contributed equally to this work. 


\section{Experimental section and supplementary Figures}

\section{Materials}

All organic solvents and chemical reagents were purchased and used as received without further purification unless otherwise noted. Poly(ethylene glycol) (PEG) diacrylate (Mw 600) and propargylamine were supplied by Aladdin. Rhodamine-PEG$\mathrm{N}_{3}$ was supplied by Shanghai ToyongBio. 2-Cholrotrityl chloride resin, $N-(9$ Fluorenylmethoxycarbonyl)(Fmoc)-protected amino acids were purchased from GL Biochem Ltd. NIR-797 isothiocyanate, 1, 2-bis(2-aminoethoxy)ethane, Boc-Lys(Boc)$\mathrm{OH}, 1-\mathrm{Hydroxybenzo-triazole}(\mathrm{HOBt})$ and trisodium citrate dihydrate were obtained from sigma-Aldrich.

\section{Synthesis of acrylate terminated poly $(\beta$-amino ester $)$ containing alkynyl groups}

The acrylate or alkynyl terminated poly $(\beta$-amino ester) was prepared by PEGDA and propargylamine through Michael addition. Briefly, $612 \mathrm{mg}$ of PEGDA (1.02 mmol, Mw 600) and $55 \mathrm{mg}$ of propargylamine were added into a flask, and stirred at $50{ }^{\circ} \mathrm{C}$ under nitrogen protection for $6 \mathrm{~h}$. The reaction mixture was heated and stirred at $80{ }^{\circ} \mathrm{C}$ for another $6 \mathrm{~h}$. Thereafter, it was heated and stirred at $90{ }^{\circ} \mathrm{C}$ for overnight. The synthesized PAEs were purified by dialyzing against distilled water for $12 \mathrm{~h}$ in a dialysis bag (Mw cutoff, $1000 \mathrm{Da}$, Vikase) to obtain acrylate terminated poly $(\beta$-amino ester) bearing alkynyl groups.

Synthesis of Fmoc-L-Lys( $\left.\mathrm{N}_{3}\right)$ and NGF conjugated poly( $\beta$-amino ester) via click reaction

Briefly, poly( $\beta$-amino ester) containing alkynyl groups (195 mg), Fmoc-Lys( $\left.\mathrm{N}_{3}\right)$ (39 $\mathrm{mg}, 0.1 \mathrm{mmol})$ and copper sulfate pentahydrate $(5.0 \mathrm{mg}, 0.02 \mathrm{mmol})$ were dispersed under nitrogen protection in $5 \mathrm{~mL}$ of $\mathrm{THF} / \mathrm{H}_{2} \mathrm{O}$. Then, $5 \mathrm{~mL}$ of ascorbic acid (1.8 $\mathrm{mg}$, $0.01 \mathrm{mmol}$ ) aqueous medium was added to the mixture, and further stirred for another $3 \mathrm{~h}$. The organic solvent was evaporated under reduced pressure, and the condensed mixture was dialyzed (Mw cutoff, $1000 \mathrm{Da}$ ) against distilled water. Finally, the dialyzed solution was freeze-dried in a lyophilizer. Similarly, NGF conjugated poly $(\beta$-amino ester) was synthesized Lys- $\mathrm{N}_{3}$ containing peptide and poly $(\beta$-amino ester) containing alkynyl groups. 


\section{Synthesis of CYIGSR terminated poly $(\beta$-amino ester $)$ via thio-ene reaction}

CYIGSR (10 mg, $0.014 \mathrm{mmol})$ and acrylate terminated poly $(\beta$-amino ester) (42 $\mathrm{mg}$ ) were dissolved in $5 \mathrm{~mL}$ of PBS (pH7.4, 0.05 M), and stirred at room temperature for $10 \mathrm{~h}$. After that, the mixture was dialyzed against distilled water at room temperature for $12 \mathrm{~h}$ and freeze-dried using a lyophlizer. Cysteine terminated poly $(\beta$-amino ester $)$ and CYIGSR terminated/NGF conjugated poly( $\beta$-amino ester) were synthesized under a similar procedure through thio-ene reaction.

\section{Synthesis of Lys-G4 dendritic star poly( $\beta$-amino esters) (Lys-G4-PAE)}

Briefly, dendrimer Lys- $\mathrm{G}_{4}\left(3.9 \mathrm{mg}, 0.001 \mathrm{mmol}\right.$, synthesis of Lys- $\mathrm{G}_{1} \sim \mathrm{Lys}_{-}-\mathrm{G}_{4}$ was shown in Scheme S2), acrylate terminated poly( $\beta$-amino ester) (400 mg) and DIPEA (13 mg, $0.1 \mathrm{mmol}$ ) were dissolved in $5 \mathrm{~mL}$ of anhydrous DMF. The resulting mixture was stirred at $80{ }^{\circ} \mathrm{C}$ under nitrogen protection for $72 \mathrm{~h}$. The organic solvent was removed under reduced pressure, the crude product was dialyzed (Mw cutoff 5000) against distilled water and freeze-dried using a lyophlizer.

\section{pKa mesurements}

The pKa of acrylate/alkynyl terminated PAEs containing alkynyl groups were measured by acid-base titration method. $150 \mathrm{mg}$ of acrylate/alkynyl terminated PAEs containing alkynyl groups were dissolved in $15 \mathrm{~mL}$ of hydrochloric acid solution $(0.01$ M). $\mathrm{pH}$ titration was conducted by adding $50 \mu \mathrm{L}$ of $0.1 \mathrm{M}$ sodium hydroxide solution, and then $\mathrm{pH}$ values were monitored by a Mettler Toledo $\mathrm{pH}$ meter. $\mathrm{pKa}$ values were determined as the $\mathrm{pH}$ in the middle of two equivalent points in the titration curve.

\section{Characterization}

${ }^{1} \mathrm{H}$ and ${ }^{13} \mathrm{C}$ Nuclear magnetic resonance (NMR) spectra were performed on a Bruker AVANCE III HD 400 spectrometer. Fourier Transform Infrared (FT-IR) Spectra were recorded on a Nicolet IS50 (Thermo Fisher Scientific) FT-IR spectrometer. Gel Permeation Chromatography was conducted using Waters 1515, and molecular weight was determined using standard PEG. Transmission Electron Microscopy (TEM) images of CYIGSR terminated/NGF conjugated PAE was taken on a JEOL JEM-1230 instrument. After dropped onto a copper grid, dispersed PAE $(5 \mathrm{mg} / \mathrm{mL})$ was negatively stained by phosphotungstic acid (1\%) before TEM observation. Mean hydrodynamic 
diameter, size distribution and polydispersity of micelles in distilled water were measured by a Dynamic Light Scattering (DLS, 90plus Zeta, Brookhaven). Zeta potentials of micelles were determined by a Zetaplus apparatus (90plus Zeta, Brookhaven). DLS and Zeta potential analyses were conducted at least three times, and the results were the average of these measurements.

\section{Cell culture}

The L929 fibroblasts cells were cultured in Dulbecco's modified Eagle medium (DMEM) medium supplemented with $10 \%$ fetal bovine serum (FBS), 100units/mL of penicillin and $100 \mu \mathrm{g} / \mathrm{mL}$ of streptomycin. The cells were grown in a humidified incubator under a $5 \% \mathrm{CO}_{2}$ atmosphere at $37^{\circ} \mathrm{C}$.

All experimental procedures with animals in this study were approved by Institutional Animal Care and Use Committee at Nantong University, and conducted under the guidelines of Care and Use of Laboratory Animals of Nantong University. Primary rat Schwann cells were isolated from sciatic nerves of one-day-old SpragueDawley (SD) rats. The isolated sciatic nerves were collected, and chopped into 1-2 mm segments. The chopped nerves were incubated with collagenase $(1 \%)$ and trypsin $(0.125 \%)$ at $37^{\circ} \mathrm{C}$ for 40 min. DMEM medium containing $10 \%$ FBS was added to the suspension to terminate the enzyme activity. The centrifuged cells were planted in polyL-lysine (PLL) pre-coated plates, and grown in DMEM medium supplemented with $10 \%$ FBS in a $5 \% \mathrm{CO}_{2}$ humidified atmosphere. The cells were treated with cytosine arabinoside $(10 \mu \mathrm{M})$ for one day in order to eliminate fibroblasts cells, and then incubated with DMEM medium containing $10 \% \mathrm{FBS}, 2 \mathrm{ng} / \mathrm{mL}$ heregulin $\beta-1$ and $2 \mu \mathrm{L}$ forskolin for two days. After that, the purified Schwann cells were cultured in DMEM medium supplemented with $10 \%$ FBS.

Dorsal root ganglion (DRG) neurons were isolated from 14 days of pregnant SD rats. The isolated DRG were cultured in Neurobasal medium supplemented with B27 (1\%), 100 units/mL of penicillin, $100 \mu \mathrm{g} / \mathrm{mL}$ of streptomycin, nerve growth factor (50 $\mathrm{ng} / \mathrm{mL}$ ) and $2 \mathrm{mM}$ L-glutamine in a $5 \% \mathrm{CO}_{2}$ humidified atmosphere. DRG neurons were then purified with Neurobasal medium containing $10 \mu \mathrm{M}$ 5-Fluoro-2'deoxyuridine (FUdR), $10 \mu \mathrm{M}$ cytosine arabinoside and $10 \mu \mathrm{M}$ uridine for two days. 


\section{Cell viability assay}

The cell viability of samples was examined by [3-(4, 5-dimethylthiazol-2-yl)-2, 5-diphenyltetrazolium bromide] (MTT) assay. The cells were planted into 96-well plates at a density of 5000 cells per well, and incubated in $100 \mu \mathrm{L}$ culture medium supplemented a series of samples and $10 \% \mathrm{FBS}$ at $37^{\circ} \mathrm{C}$. After a predetermined period, the culture medium was removed, and MTT solution $(10 \mu \mathrm{L}, 5 \mathrm{mg} / \mathrm{mL})$ was added into each well. The mixture was incubated for $4 \mathrm{~h}$ at $37^{\circ} \mathrm{C}$, and the supernatant was removed. $100 \mu \mathrm{L}$ of DMSO was added to each well, and the values of plate were determined at $570 \mathrm{~nm}$ on a microplate spectrofluorometer. At least four independent samples were measured, and then averaged. The cell viability was calculated by the following formula:

$$
\text { Cell viability } \%=\frac{\text { Absorbance test cells }}{\text { Absorbance controlled cells }} \times 100 \%
$$

\section{Cell labeling and imaging}

Schwann cells were seeded into 12 well-plates $\left(1 \times 10^{4}\right.$ cells/well), and incubated with PBS (control), $1 \mathrm{mg} / \mathrm{mL}$ of Rhodamine-PEG-( $\left.\mathrm{N}_{3}\right)$ modified poly( $\beta$-amino ester), NGF conjugated poly $(\beta$-amino ester $)$ and CYIGSR terminated/NGF conjugated poly $(\beta$ amino ester) for $4 \mathrm{~h}$. Then, Schwann cells were incubated with Lyso Tracker ${ }^{\mathrm{TM}}(1: 1000$ dilution) or Mito Tracker (1:1000 dilution) for $30 \mathrm{~min}$. After washed with PBS, the cells were observed by confocal laser scanning microscopy. Quantitative analysis of fluorescent images was performed using ImageJ software (1.52s, NIH). Co-localization correlation coefficients (Pearson's coefficient) of poly $(\beta$-amino ester) micelles in mitochondria or lysosomes were quantified by Colocalization analysis in ImageJ software $(1.52 \mathrm{~s}, \mathrm{NIH})$. Three independent samples were measured, and then averaged.

\section{Peptide competition assay}

Primary Schwann cells were planted a density of 8000 cells/well in 96-well plates. The planted cells were cultured overnight at $37^{\circ} \mathrm{C}$, and then the culture medium was removed. The cells were preincubated with different concentrations of NGF peptide or CYIGSR peptide $(25-500 \mu \mathrm{g} / \mathrm{mL})$ at $37{ }^{\circ} \mathrm{C}$ for $20 \mathrm{~min}$, respectively. Thereafter, Rhodamine-labelled CYIGSR/PAE/NGF $(1 \mathrm{mg} / \mathrm{mL})$ were added to culture medium. Schwann cells were further incubated at $37{ }^{\circ} \mathrm{C}$ for $4 \mathrm{~h}$, and then washed three times 
with PBS. The fluorescence intensities were measured by a microplate reader at an excitation wavelength of $554 \mathrm{~nm}$ and an emission wavelength of $593 \mathrm{~nm}$. The relative fluorescence was calculated by subtracting autofluorescence. Four independent samples were measured, and then averaged.

\section{Flow cytometry assay}

Schwann cells apoptosis was conducted by Annexin-FITC/Propidium iodide detection Kit. Briefly, Schwann cells were seeded onto 6-well plates and co-incubated in DMEM medium supplemented with $10 \%$ fetal bovine serum (FBS). Then, Schwann cells were randomly treated with PBS (control), poly( $\beta$-amino ester), NGF conjugated $\operatorname{poly}(\beta$-amino ester) and CYIGSR terminated/NGF conjugated poly( $\beta$-amino ester). After two days, Schwann cells were stained by Annexin-FITC/Propidium iodide for 0.5 $\mathrm{h}$ at dark environment. Schwann cells were analyzed by a flow cytometer. Three independent samples were measured, and then averaged.

\section{Immunofluorescence}

The isolated DRG neurons were cultured in Neurobasal medium supplemented with B27 (1\%) and $2 \mathrm{mM} \mathrm{L-glutamine} \mathrm{for} 12 \mathrm{~h}$ in a 5\% $\mathrm{CO}_{2}$ humidified atmosphere. After replenished with new Neurobasal medium, the neurons were treated with different concentrations of NGF peptide or NGF conjugated PAE compound for three days. Neurons were co-incubated with or without nerve growth factor $(50 \mathrm{ng} / \mathrm{mL})$ as positive and negative control, respectively. Cultured DRG were fixed with 4\% paraformaldehyde for $1 \mathrm{~h}$, and incubated in blocking buffer. Then, DRG neurons were stained by monoclonal anti-neurofilament 160/200 antibody (1:500 dilution, Sigma). Alexa Fluor 488-conjugated Affinipure Goat Anti-Mouse IgG was used as secondary antibodies (1:500 dilution, Proteintech) to visualize neurite outgrowth. The fluorescent images were observed by a fluorescence microscope (Axio Imager M2, Zeiss). The neurite length of DRG was measured from edge of cell body to the end of neurite using ImageJ software $(1.52 \mathrm{~s}, \mathrm{NIH})$. At least sixteen neurites were measured, and then averaged.

\section{Brain Injury model}

ICR Mice (male, 18-22 g) were anesthetized by intraperitoneal injection with 
pentobarbital sodium $(10 \mathrm{mg} / \mathrm{kg}$ in saline). After sterilization with iodophor, the scalp was precisely incised along the middle-line to expose the skull. The cortical lesion was made on the left parietal skull using bregma and lambda as references. A liquid nitrogen cooled stainless steel rod with $3 \mathrm{~mm}$ diameter was placed on left skull for one minute to make brain injury model. The skin was sutured by a surgical needle.

\section{Bio-distribution}

Briefly, brain injured mice were randomly divided into four groups $(n=3)$. The mice were administrated with NGF formulations (NIR-797 modified NGF peptide, NGF conjugated PAE and CYIGSR terminated/NGF conjugated PAE) at a dosage of $100 \mu \mathrm{g}$ (equivalent NGF peptide) per mouse via intravenous injection. At predetermined time points, the animals were sacrificed, and then major internal organs were harvested for ex vivo imaging. The fluorescence intensity (excitation $=750 \mathrm{~nm}$, emission $=800 \mathrm{~nm}$ ) of NIR-797 conjugated NGF peptide, NGF conjugated PAE and CYIGSR terminated/NGF conjugated PAE in the organs were determined by Imaging J software.

\section{Pharmacokinetic analysis}

The pharmacokinetic profile of CYIGSR/PAE/NGF was conducted using healthy animals. ICR mice (male, 20 22 g) were administrated with NIR-labelled CYIGSR/PAE/NGF via tail vein (equivalent $100 \mu \mathrm{g}$ NGF peptide per mouse). After the pre-determined periods ( $5 \mathrm{~min}, 15 \mathrm{~min}, 30 \mathrm{~min}, 1 \mathrm{~h}, 3 \mathrm{~h}, 6 \mathrm{~h}, 12 \mathrm{~h}, 24 \mathrm{~h}$ and $32 \mathrm{~h}$ ), 0.3 $\mathrm{mL}$ of blood was collected from each mouse for ex vivo imaging (IVIS Lumina, Perkin Elmer). Thereafter, the animals were sacrificed. The fluorescence intensities of blood samples were measured by Imaging system. The quantitative pharmacokinetic results were determined by a pre-determined standard curve. At least four independent samples were measured, and then averaged.

\section{Penetration analysis}

Briefly, brain-injured ICR mice were intravenously administrated with saline, Rhodamine-PEG-N 3 labelled PAE, PAE/NGF and CYIGSR/PAE/NGF (equivalent 100 $\mu \mathrm{g}$ NGF peptide per mouse). The animals were sacrificed at six hours post-injection. The harvested brains were fixed with $4 \%$ paraformaldehyde, and dissected into $10 \mu \mathrm{m}$ 
coronal slices. After blocked with $5 \%$ BSA for $2 \mathrm{~h}$, the blocked slices were incubated with CD31 antibody $\left(1: 1000\right.$, Proteintech) at $4{ }^{\circ} \mathrm{C}$ overnight. Then, slices were further incubated with $\lg G$ H\&L (Alexa Fluor 488, Abcam). Finally, the slices were stained with Hoechst and observed by a Zeiss fluorescence microscope.

\section{Blood-brain barrier permeability}

Brain injured mice were randomly divided into four groups $(n=3)$, and treated with saline, NGF peptide, NGF conjugated PAE and CYIGSR terminated/NGF conjugated PAE at a dosage of $100 \mu \mathrm{g} /$ mouse (equivalent NGF peptide) via intravenous injection, respectively. The therapeutic agents were injected via tail vein at day 2, day 4 and day 6. After eight days treatments, Evans blue $(20 \mathrm{mg} / \mathrm{mL}$ in saline, $4 \mathrm{~mL} / \mathrm{kg})$ was administrated via tail vein. After two hours, the mice were anesthetized with pentobarbital sodium, and then sacrificed. The brain tissues were isolated, and then cortex was harvested. The collected cortex was homogenized in $50 \%$ trichloro-acetic acid solution. After centrifugation, the supernatant was collected and the absorbance of Evans blue was measured by a UV-vis spectrometer at $620 \mathrm{~nm}$. The Evans blue concentration was determined using a pre-established standard curve.

\section{Histological studies and immunofluorescence study}

The photograph of the isolated brain was taken by a digital camera. Then, injured area of brain was dissected into 1-mm coronal slice using a brain matrix (RWD, Shenzhen), and stained by 2,3,5-triphenyltetrazolium chloride (TTC, $2 \%$ ) in PBS. The stained slices were visualized by immersing in $10 \%$ formalin PBS solution. For immunofluorescence staining, the collected brains were fixed with $4 \%$ paraformaldehyde in PBS and dissected into $10 \mu \mathrm{m}$ coronal slices. After blocked with $5 \%$ BSA for $2 \mathrm{~h}$, the blocked slices were incubated with rabbit anti-GFAP Antibody (1:1000, Proteintech) and Anti- $\beta$-Tubulin III Neuronal Marker antibody (1:1000, Abcam) at $4{ }^{\circ} \mathrm{C}$ overnight. Then, slices were further incubated with goat anti-rabbit $\lg G$ H\&L (Alexa Fluor 488, Abcam) and goat anti-mouse lgG H\&L (Cy3 pre-adsorbed, Abcam). Finally, the slices were stained with Hoechst and observed by a Zeiss fluorescence microscope.

\section{RT-PCR}


Gene expressions of $\beta$-tubulin were quantified by qRT-PCR analysis. After eight days treatments, brain injured mice were sacrificed and the injured area of brain were collected. The collected tissues were triturated, and total RNA was isolated with TRIzol reagent (Invitrogen). The same amounts of collected RNA were reverse-transcribed into cDNA. qRT-PCR was carried out on a Real-Time PCR System (Applied Biosystem). GADPH was applied as the endogenous control to normalize the $\beta$-tubulin mRNA amount. The primer sequences of mouse GADPH (forward, 5'GGTTGTCTCCTGCGACTTCA; reverse, TGGTCCAGGGTTTCTTACTCC-3') and $\beta$-tubulin (forward, 5'-GGAAACAGCACAGCCATCC; reverse, CAGCCTCGGTGA ACTCCAT-3') were used in PCR analysis. The results are expressed as mean \pm standard deviation $(n \geq 3)$.

\section{Statistical Analysis}

All statistical analysis was conducted using GraphPad Prism 5 software. Data are expressed as mean \pm standard error unless otherwise stated, and experimental results were analyzed by Student's t-test (two tailed). ${ }^{*}$ P-values $<0.05$ was considered as significant, and $* * \mathrm{P}$-values $<0.01$ and $* * * \mathrm{P}$-values $<0.001$ were considered as highly significant. 


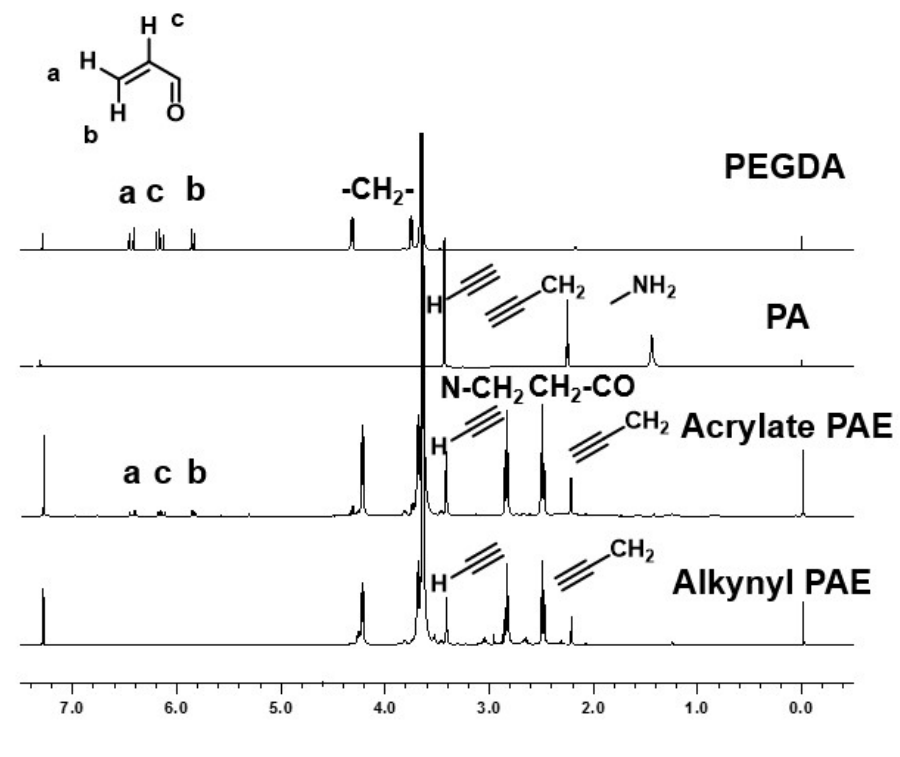

Figure S1 ${ }^{1} \mathrm{H}$ NMR spectra of PEGDA (Mw=600), 2-propynylamine (PA), acrylate and alkynyl terminated poly( $\beta$-amino esters) (PAEs). 


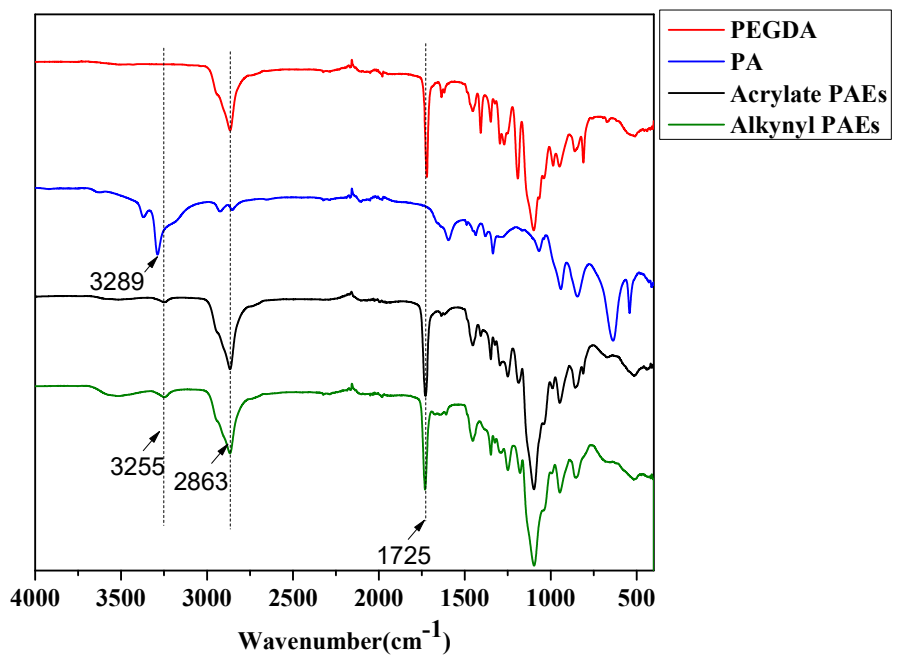

Figure S2 FT-IR spectra of PEGDA, 2-propynylamine (PA), acrylate and alkynyl terminated poly( $\beta$-amino esters) (PAEs). 
Table S1 Characterization of acrylate/alkynyl terminated PAEs.

\begin{tabular}{|c|c|c|c|c|c|c|}
\hline \multirow{2}{*}{ Polymers } & \multicolumn{2}{|c|}{ Feeding molar ratio (\%) } & \multirow{2}{*}{ Yield (\%) } & Mn & PDI & pKa \\
\cline { 2 - 3 } & PEGDA & PA & & & & \\
\hline Acrylate terminated PAEs & 50.5 & 49.5 & 86 & 4621 & 1.95 & 5.28 \\
\hline Alkynyl terminated PAEs & 49.5 & 50.5 & 85 & 4604 & 1.93 & 5.00 \\
\hline
\end{tabular}



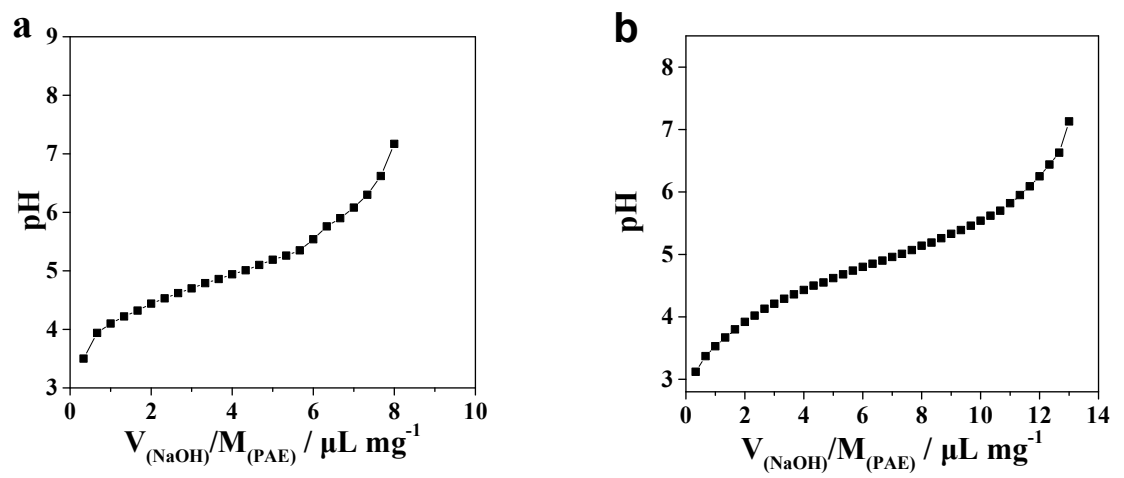

Figure S3 pH titration curves of acrylate (a) and alkynyl (b) terminated PAEs containing alkynyl groups. 


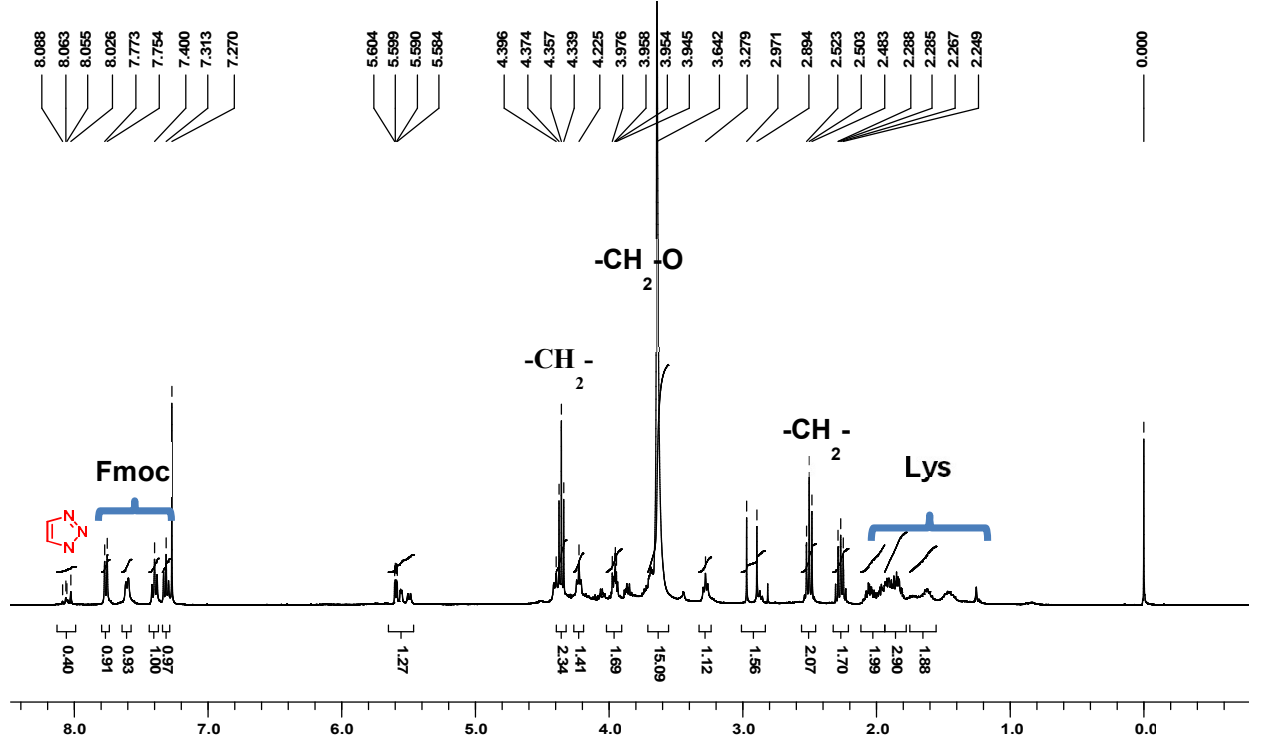

Figure S4 ${ }^{1} \mathrm{H}$ NMR spectra of Fmoc-Lys-N 3 conjugated poly $(\beta$-amino ester). 


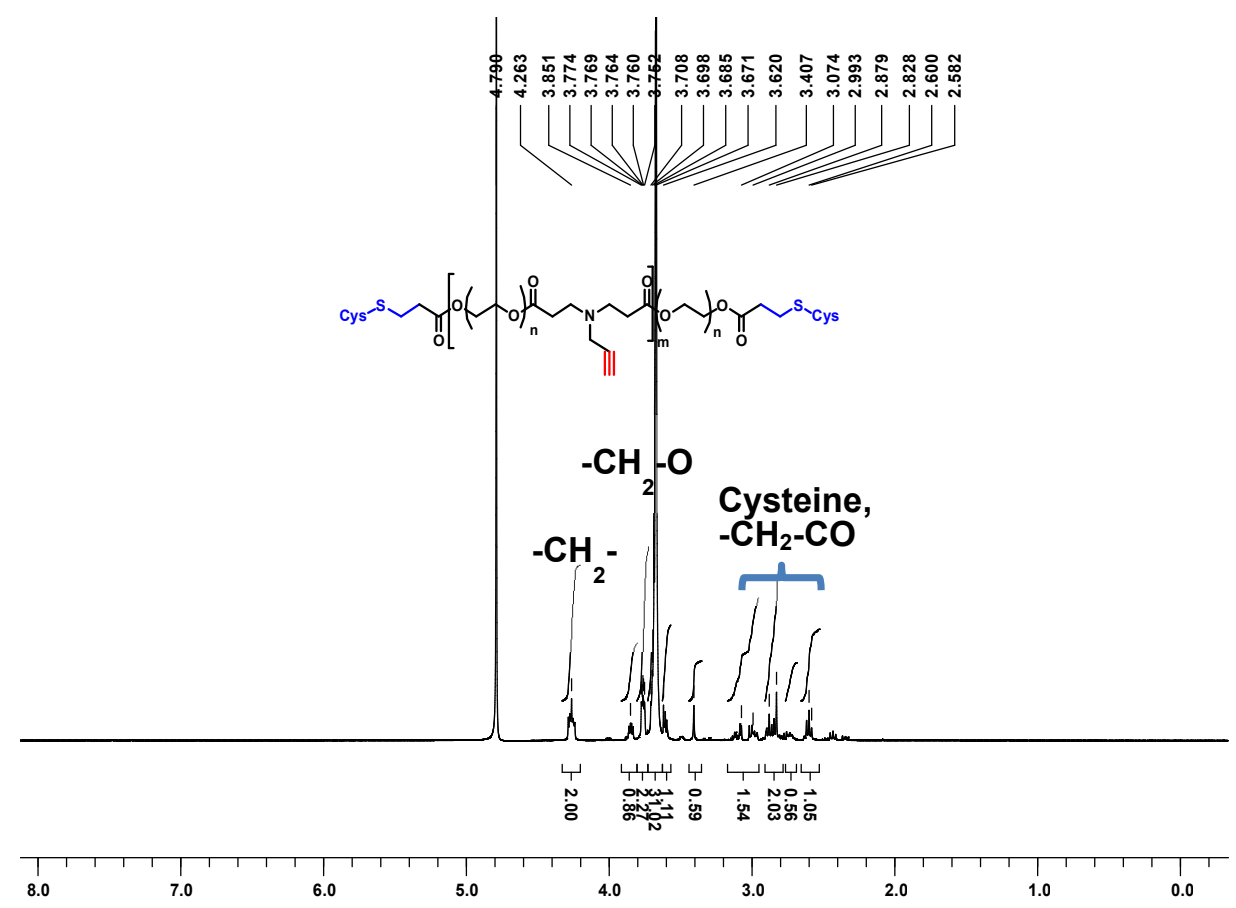

Figure S5 ${ }^{1} \mathrm{H}$ NMR spectra of cysteine terminated poly( $\beta$-amino ester). Cysteine was chosen as a model to conjugate to acrylate terminated $\operatorname{poly}(\beta$-amino ester). 


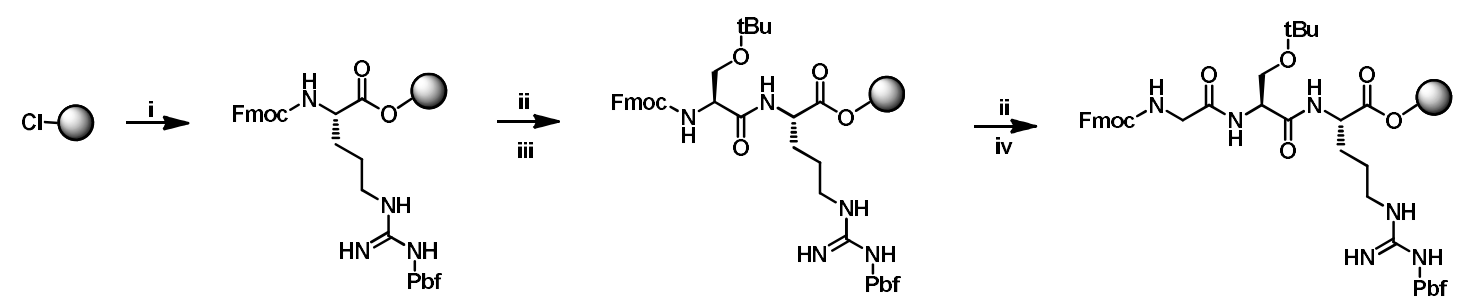<smiles>CCC(C)(C)C(C)(C)C(C)(C)C</smiles>

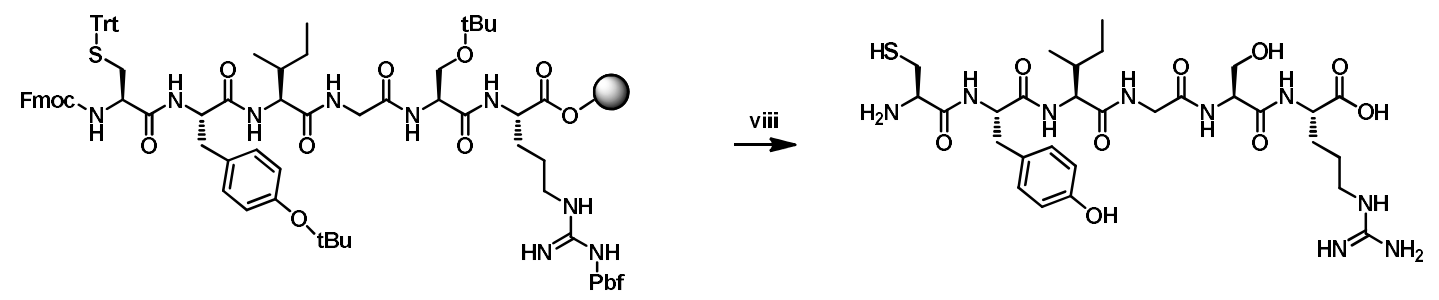

Scheme S1 (i) Fmoc-Arg(Pbf)-OH, DIEA, $\mathrm{CH}_{2} \mathrm{Cl}_{2}$; (ii) Piperidine, DMF; (iii) FmocSer(tBu)-OH, DIEA, HBTU, DMF; (iv) Fmoc-Gly-OH, DIEA, HBTU, DMF; (v) Fmoc-Ile-OH, DIEA, HBTU, DMF; (vi) Fmoc-Tyr(tBu)-OH, DIEA, HBTU, DMF; (vii) Fmoc-Cys(Trt)-OH, DIEA, HBTU, DMF; (viii) TFA, TIPS, $\mathrm{H}_{2} \mathrm{O}$.

\section{Peptides synthesis method}

CYIGSR and NGF peptide sequences were prepared by solid phase peptide synthesis. Briefly, 2-cholrotrityl chloride resin $(1.1 \mathrm{mmol} / \mathrm{g})$ was swollen by methylene chloride for 15 min at room temperature. Fmoc-amino acid with side chain protecting groups and DIPEA in DMF were added to resin, and the reaction mixture was shaken for $2 \mathrm{~h}$ at room temperature to conjugate the first amino acid. After de-protection with piperidine in DMF (20\%), the reaction mixture was shaken for 30 min. The next Fmocprotected amino acid was coupled to the peptidyl resin using HBTU and DIPEA, and shaken for $2 \mathrm{~h}$ at room temperature. The deprotection of Fmoc group and coupling amino acid to resin were repeated to obtain corresponding peptide sequences. The synthesized peptide was cleaved with trifluoroacetic acid (TFA)/triisopropylsilane (TIPS)/water (95:2.5:2.5) for $2 \mathrm{~h}$. The organic solvent was removed under reduced 
pressure, and the resulting mixture was precipitated in the ethyl ether. The precipitate was collected, and dried solid power as crude samples. All peptides were purified with a Waters Prep LC system equipped with a Waters UV-Vis 2489 detector and a standard reversed phase Daisogel C18 column. The mobile phase is used gradient methanol plus $0.1 \%$ TFA and distilled water plus $0.1 \%$ as an eluent at a flow rate of $10.0 \mathrm{~mL} / \mathrm{min}$. 


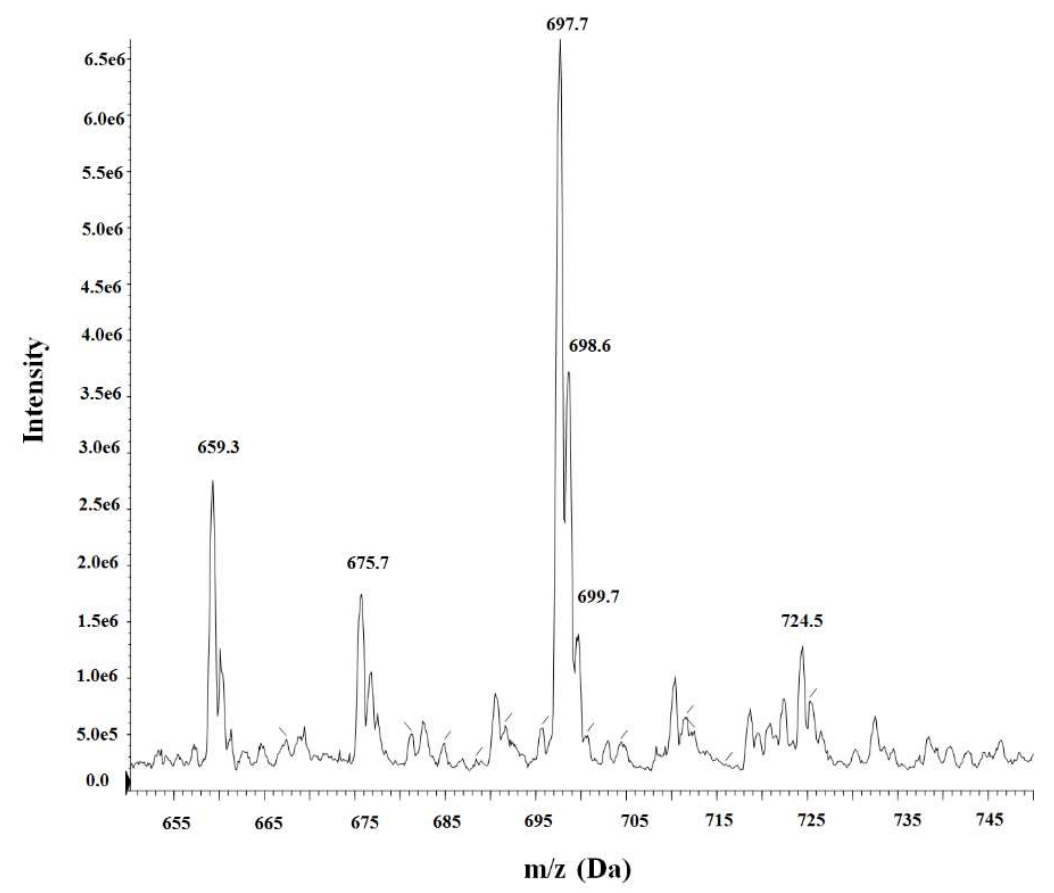

Figure S6 ESI mass spectrum of CYIGSR $\left([\mathrm{M}+\mathrm{H}]^{+}, 697.7\right)$. 


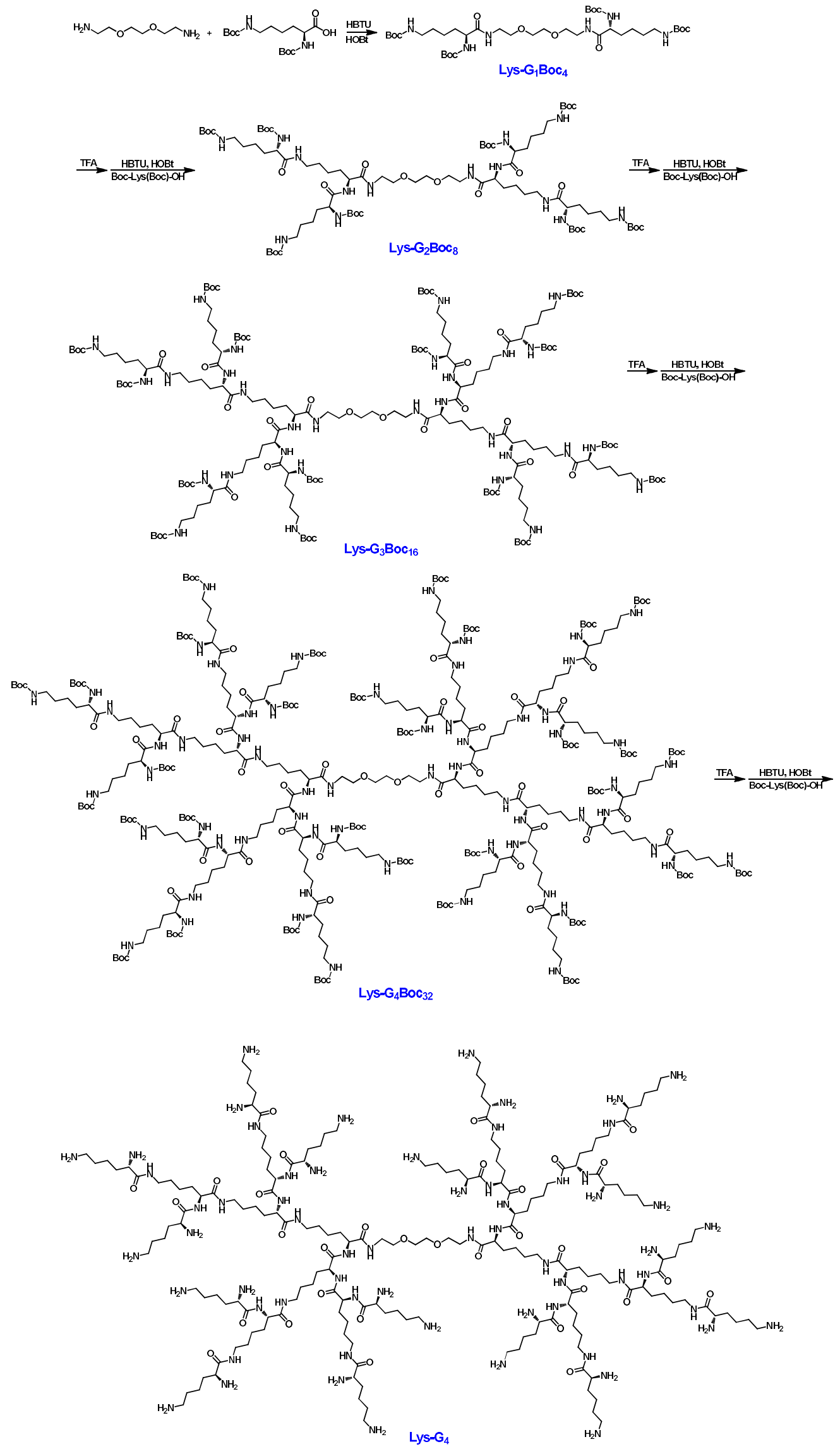

Scheme S2 Synthetic route of Lys-G 4 . 


\section{Synthesis of Lys-G $\mathrm{GBoc}_{4}$}

1, 2-bis(2-aminoethoxy)ethane (0.741 g, $5 \mathrm{mmol}$ ) and Boc-Lys(Boc)-OH (3.81 g, $11 \mathrm{mmol}$ ) were dissolved in $20 \mathrm{~mL}$ dried $N, N$-Dimethylformamide (DMF) under nitrogen atmosphere. Then, HBTU (4.36 g, $11 \mathrm{mmol})$ and HOBt (1.48 g, $11 \mathrm{mmol})$ were added to the suspension. After incubation for $24 \mathrm{~h}$ at room temperature, the solvent was evaporated and the resulting mixture was precipitated with $10 \%$ trisodium citrate dehydrate aqueous solution. The precipitate was dried, and the crude product was further purified by column chromatography with an eluant of DCM/methanol (40/1, volume ratio) to give Lys- $\mathrm{G}_{1} \mathrm{Boc}_{4}$ as a white solid (3.54 g, 88\%). ${ }^{1} \mathrm{H}$ NMR (300 MHz, $\left.\mathrm{CDCl}_{3}\right) \delta: 1.42$ (s, 36H), 1.62 (br s, 2H), 1.78 (br s, 2H), 2.17 (br s, 2H), 3.09 (br s, 2H), 3.36 (br s, 2H), 3.54 (br s, 4H), 3.58 (s, 4H), 4.12 (br s, 2H), 4.76 (br s, 2H), 5.43 (br s, 2H), 6.98 (br s, 2H). ${ }^{13} \mathrm{C} \mathrm{NMR}\left(75 \mathrm{MHz}, \mathrm{CDCl}_{3}\right) \delta: 172.48,156.16,79.83,79.11,77.24$, $70.35,69.73,54.38,39.32,32.43,29.63,28.46,28.37,22.70$.

\section{Synthesis of Lys-G2Bocs}

To a solution of Lys-G Boc $_{4}(0.804 \mathrm{~g}, 1 \mathrm{mmol})$ in $3 \mathrm{~mL}$ of DCM was added $3 \mathrm{~mL}$ of trifluoroacetic acid (TFA) at room temperature. The resulting mixture was stirred at room temperature for $2 \mathrm{~h}$. After the removal of solvents under reduced pressure, the deprotected Lys-G $\mathrm{G}_{1}$ was obtained. MALDI-TOF MS (m/z): Calcd. 404.31, founded: 405.55 for $[\mathrm{M}+\mathrm{H}]^{+}$. The collected Lys-G 1 , triethylamine and Boc-Lys(Boc)-OH (2.84 $\mathrm{g}, 8.2 \mathrm{mmol}$ ) were dissolved in $30 \mathrm{~mL}$ dried DMF under nitrogen atmosphere. Then HBTU $(3.11 \mathrm{~g}, 8.2 \mathrm{mmol})$ and HOBt $(1.11 \mathrm{~g}, 8.2 \mathrm{mmol})$ were added to the suspension. After incubation for $24 \mathrm{~h}$ at room temperature, the solvent was evaporated and the resulting mixture was precipitated with $10 \%$ trisodium citrate dihydrate aqueous solution. The precipitate was dried, and the crude product was further purified by column chromatography with an eluant of DCM/methanol (35/1, volume ratio) to give Lys- $\mathrm{G}_{2} \mathrm{Boc}_{8}$ as a white solid (1.46 g, 85\%). ${ }^{1} \mathrm{H}$ NMR $\left(300 \mathrm{MHz}, \mathrm{CDCl}_{3}\right) \delta: 1.43$ (s, 72H), 1.687 (br s, 12H), 2.15 (br s, 6H), 2.928 (br s, 2H), 3.09 (br s, 8H), 3.30 (br s, 2H), 3.56 (br s, 10H), 4.32 (br s, 2H), 4.42 (br s, 2H), 4.48 (br s, 2H), 4.82 (br s, 2H), 5.11 (br s, 2H), 5.81 (br s, 2H), 5.97 (br s, 2H), 7.42 (br s, 2H), 7.72 (br s, 3H). ${ }^{13} \mathrm{C}$ NMR (75 MHz, $\left.\mathrm{CDCl}_{3}\right) \delta: 173.89,173.34,172.29,156.38,156.20,156.08,79.94$, $79.82,78.90,78.82,77.30,70.25,69.67,53.95,40.28,40.04,39.44,39.04,39.02,33.38$, $32.99,32.10,29.37,28.46,22.82,22.56$.

\section{Synthesis of Lys-G3Boc 16}

To a solution of Lys- $\mathrm{G}_{2} \mathrm{Boc}_{8}(0.859 \mathrm{~g}, 0.5 \mathrm{mmol})$ in $3 \mathrm{~mL}$ of DCM was added 3 
$\mathrm{mL}$ of trifluoroacetic acid (TFA) at room temperature. The resulting mixture was stirred at room temperature for $2 \mathrm{~h}$. After the removal of solvents under reduced pressure, the deprotected Lys-G $\mathrm{G}_{2}$ was obtained. MALDI-TOF MS (m/z): Calcd. 916.69, founded: 939.44 for $[\mathrm{M}+\mathrm{Na}]^{+}$. The collected Lys- $\mathrm{G}_{2}$, triethylamine and Boc-Lys(Boc)-OH (2.84 g, $8.2 \mathrm{mmol}$ ) were dissolved in $30 \mathrm{~mL}$ dried DMF under nitrogen atmosphere. Then HBTU (3.11 g, $8.2 \mathrm{mmol})$ and HOBt (1.11 g, $8.2 \mathrm{mmol})$ were added to the suspension. After incubation for $24 \mathrm{~h}$ at room temperature, the solvent was evaporated and the resulting mixture was precipitated with $10 \%$ trisodium citrate dihydrate aqueous solution. The precipitate was dried, and the crude product was further purified by column chromatography with an eluant of DCM/methanol (30/1, volume ratio) to give Lys-G ${ }_{3}$ Boc $_{16}$ as a white solid (1.45 g, 82\%). ${ }^{1} \mathrm{H}$ NMR (300 MHz, $\left.\mathrm{CDCl}_{3}\right) \delta: 1.41$ (s, 72H), 1.42 (s, 72H), 1.68 (br, 36H), 3.00 (br s, 14H), 3.16 (br s, 8H), 3.35 (br s, 4H), 3.53 (br s, 4H), 3.58 (br s, 4H), 3.98 (br s, 6H), 4.28 (br s, 6H), 7.97 (br s, 8H), 8.06 (br

s, $4 \mathrm{H}) .{ }^{13} \mathrm{C}$ NMR $\left(400 \mathrm{MHz}, \mathrm{CDCl}_{3}\right) \delta: 175.03,173.83,158.33,157.60,80.74,80.61$, $79.83,79.36,79.04,78.72,71.27,70.43,55.97,54.55,40.98,40.47,40.13,33.33,32.79$, $30.51,29.75,28.98,24.10$.

\section{Synthesis of Lys-G $\mathrm{GBoc}_{\mathbf{3}}$ and Lys-G 4}

To a solution of Lys- $\mathrm{G}_{3} \mathrm{Boc}_{16}(0.886 \mathrm{~g}, 0.25 \mathrm{mmol})$ in $3 \mathrm{~mL}$ of DCM was added 3 $\mathrm{mL}$ of trifluoroacetic acid (TFA) at room temperature. The resulting mixture was stirred at room temperature for $2 \mathrm{~h}$. After the removal of solvents under reduced pressure, the deprotected Lys-G3 was obtained. MALDI-TOF MS ( $m / z)$ : Calcd. 1941.45, founded: 1942.85 for $[\mathrm{M}+\mathrm{H}]^{+}$. The collected Lys-G 3 , triethylamine and Boc-Lys(Boc)-OH (2.84 g, $8.2 \mathrm{mmol}$ ) were dissolved in $30 \mathrm{~mL}$ dried DMF under nitrogen atmosphere. Then HBTU (3.11 g, $8.2 \mathrm{mmol})$ and HOBt $(1.11 \mathrm{~g}, 8.2 \mathrm{mmol})$ were added to the suspension. After incubation for $24 \mathrm{~h}$ at room temperature, the solvent was evaporated and the resulting mixture was precipitated with $10 \%$ trisodium citrate dihydrate aqueous solution. The precipitate was dried, and the crude product was further purified by column chromatography with an eluant of DCM/methanol (20/1, volume ratio) to give Lys-G $\mathrm{G}_{4} \mathrm{Boc}_{32}$ as a white solid (1.42 g, 79\%). ${ }^{1} \mathrm{H}$ NMR (300 MHz, $\left.\mathrm{CDCl}_{3}\right) \delta: 1.41$ (s, 144H), 1.42 (s, 144H), 1.68 (br, 88H), 3.02 (br s, 30H), 3.15 (br s, $22 \mathrm{H}), 3.53$ (br s, 4H), 3.58 (br s, 4H), 3.99 (br s, $12 \mathrm{H}$ ), 4.28 (br s, 12H), 7.98 (br s, 18H), 8.09 (br s, 6H). ${ }^{13} \mathrm{C}$ NMR $\left(75 \mathrm{MHz}, \mathrm{CDCl}_{3}\right) \delta: 175.38,174.22,158.62,158.22,157.91,80.82,80.69$, 79.32, 71.49, 70.62, 56.30, 54.84, 41.19, 40.34, 33.47, 32.98, 30.77, 30.02, 29.05, 24.38. To a solution of Lys- $\mathrm{G}_{4} \mathrm{Boc}_{32}(0.899 \mathrm{~g}, 0.125 \mathrm{mmol})$ in $3 \mathrm{~mL}$ of DCM was added $3 \mathrm{~mL}$ 
of trifluoroacetic acid (TFA) at room temperature. The resulting mixture was stirred at room temperature for $2 \mathrm{~h}$. After the removal of solvents under reduced pressure, the deprotected Lys-G4 was obtained. MALDI-TOF MS ( $\mathrm{m} / \mathrm{z})$ : Calcd. 3991.97, founded: 3993.33 for $[\mathrm{M}+\mathrm{H}]^{+}$. 

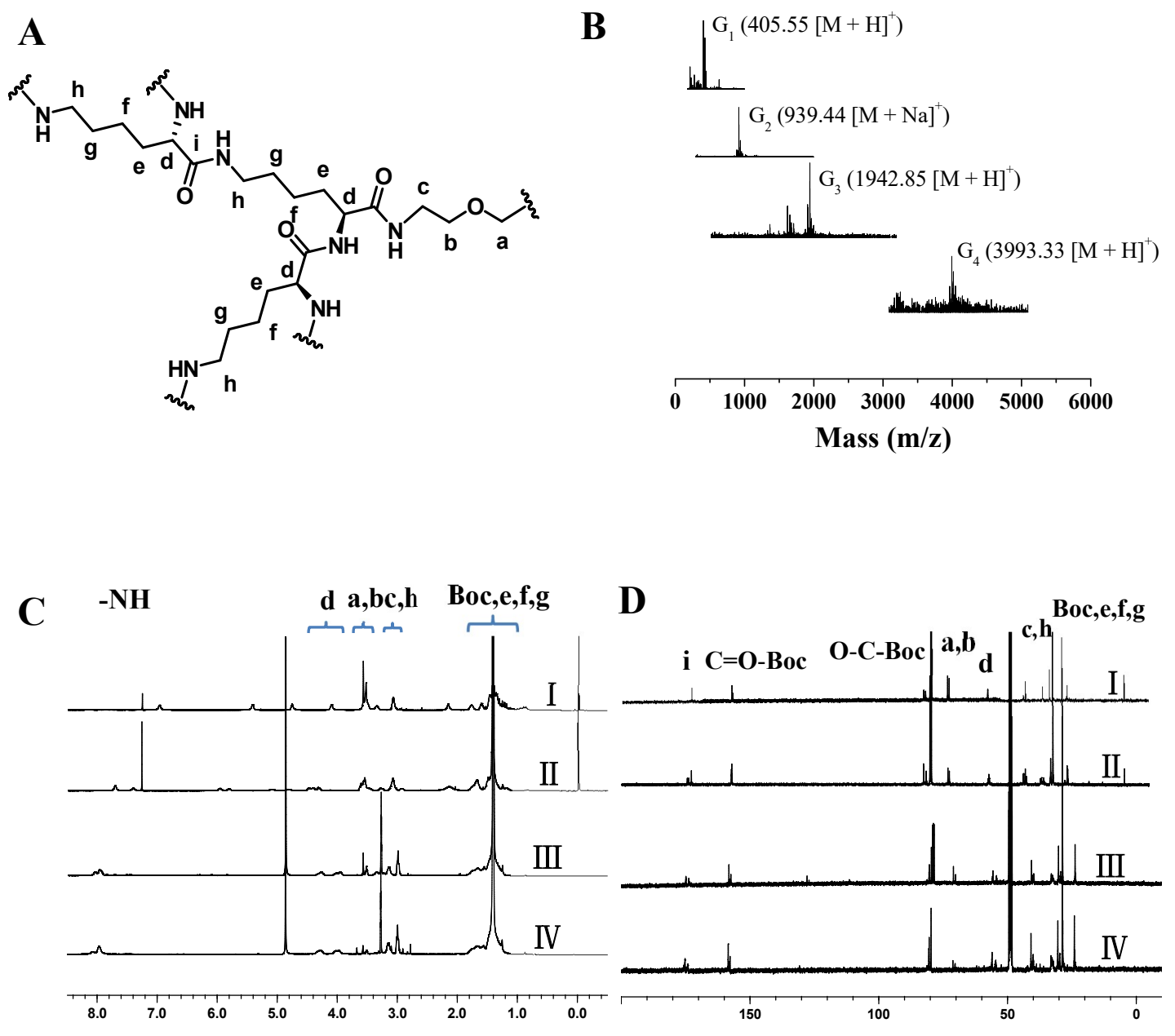

Figure S7 (A) Chemical structure of Lys-dendrimers; (B) MALDI-TOF mass spectra; ${ }^{1} \mathrm{H}$ NMR (C) and ${ }^{13} \mathrm{C}$ NMR (D) of Lys-G $\mathrm{Boc}_{4}$ (I), Lys-G Boc $_{8}$ (II), Lys-G $\mathrm{Boc}_{16}$ (III) and Lys-G44 $B_{32}(I V)$. 


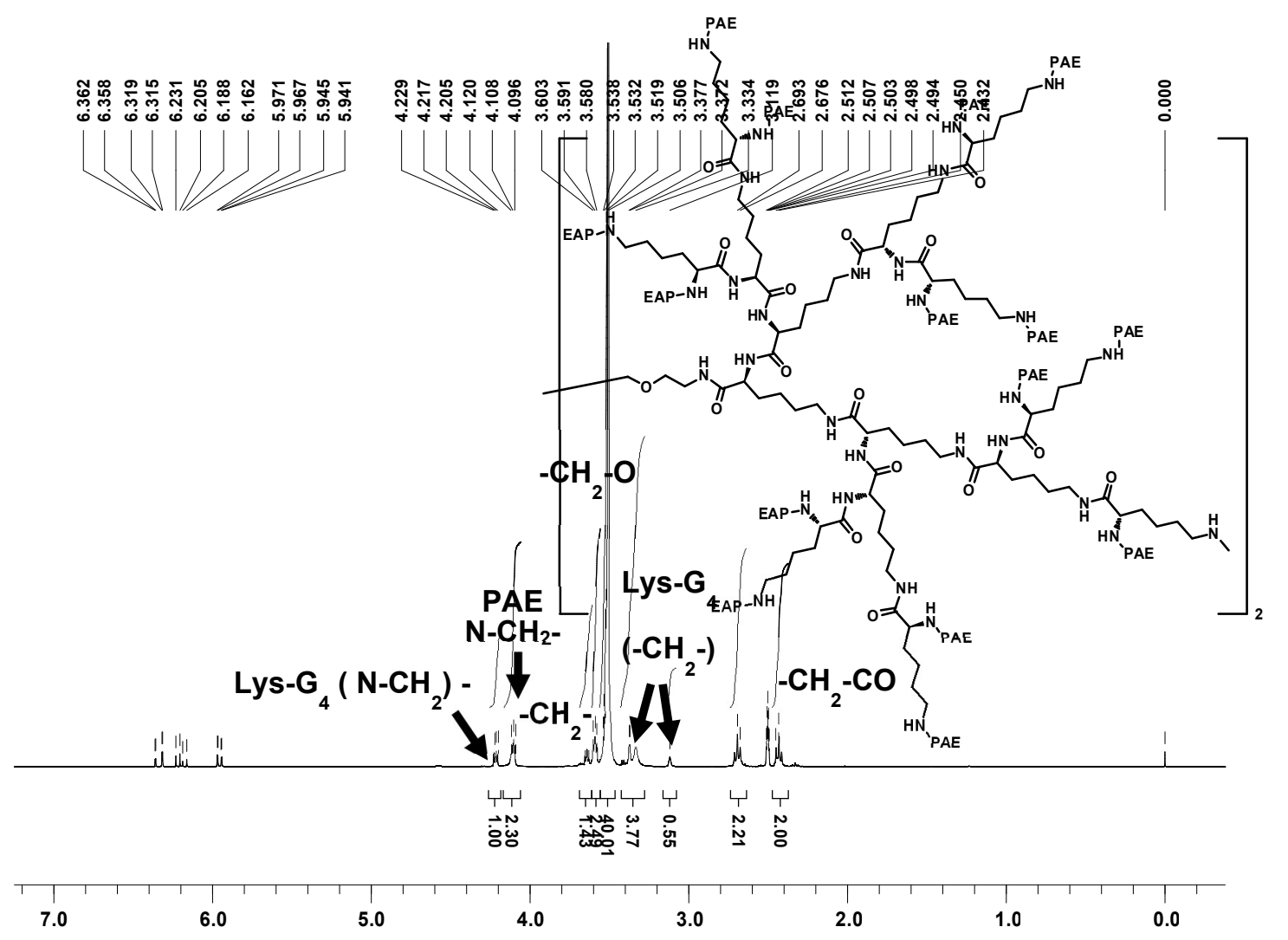

Figure S8 ${ }^{1} \mathrm{H}$ NMR spectra of Lys- $\mathrm{G}_{4}$ terminated poly $(\beta$-amino ester $)$. 


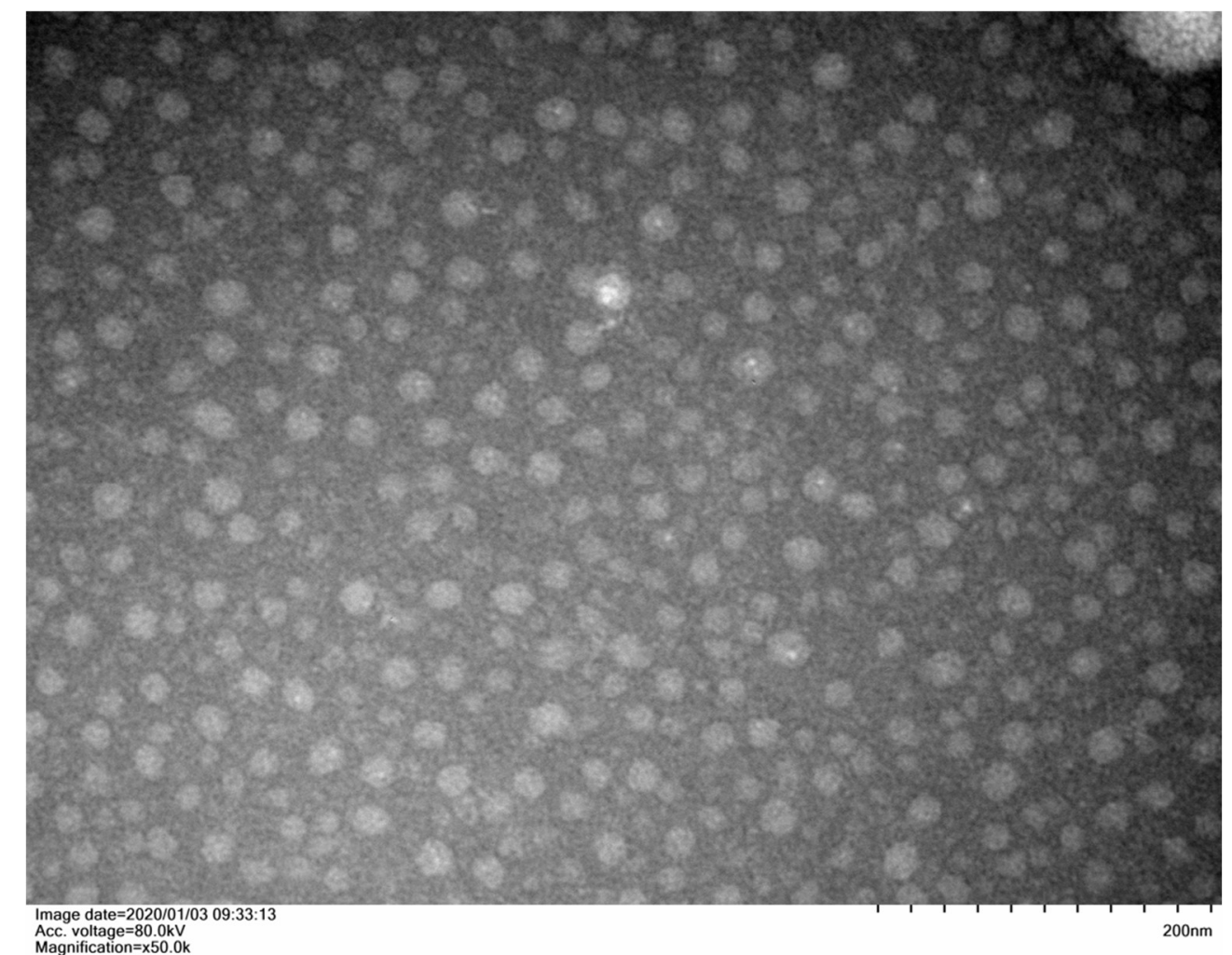

Figure S9 TEM image of CYIGSR/PAE/NGF. 


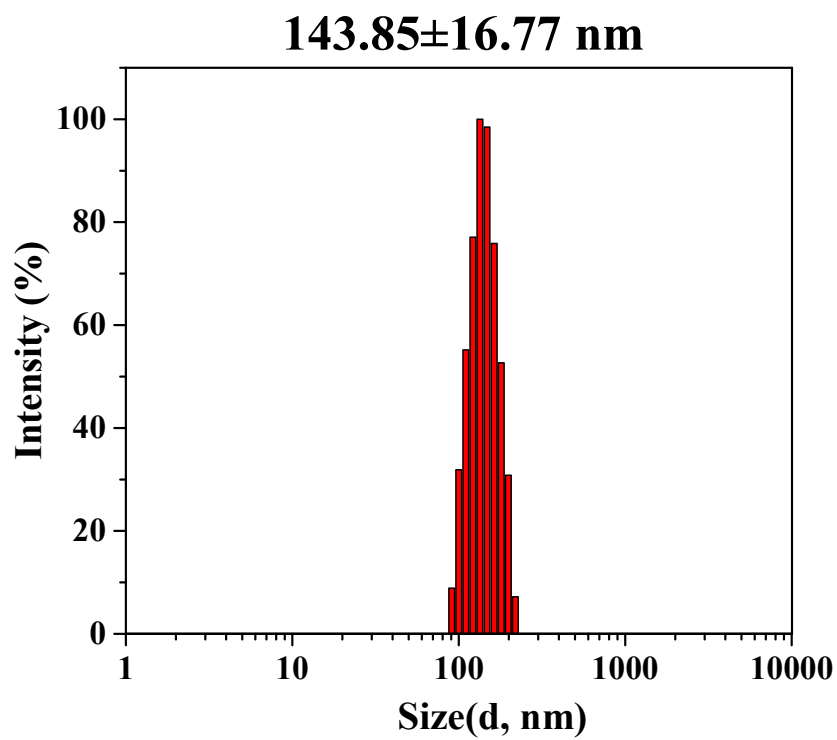

Figure S10 Hydrodynamic diameter distribution of CYIGSR/PAE/NGF micelles. 


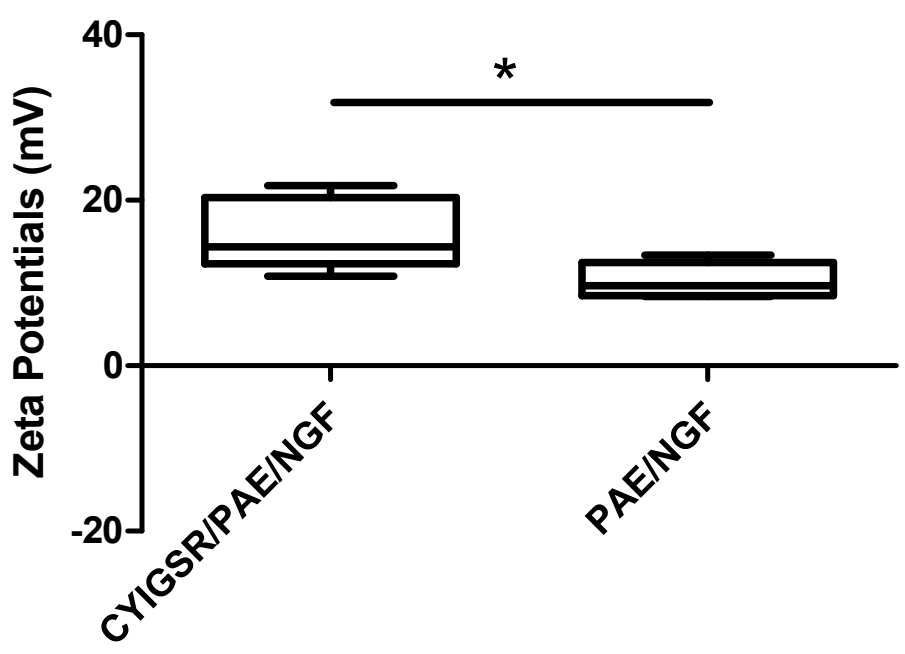

Figure S11 Zeta potentials of CYIGSR/PAE/NGF and PAE/NGF micelles. 


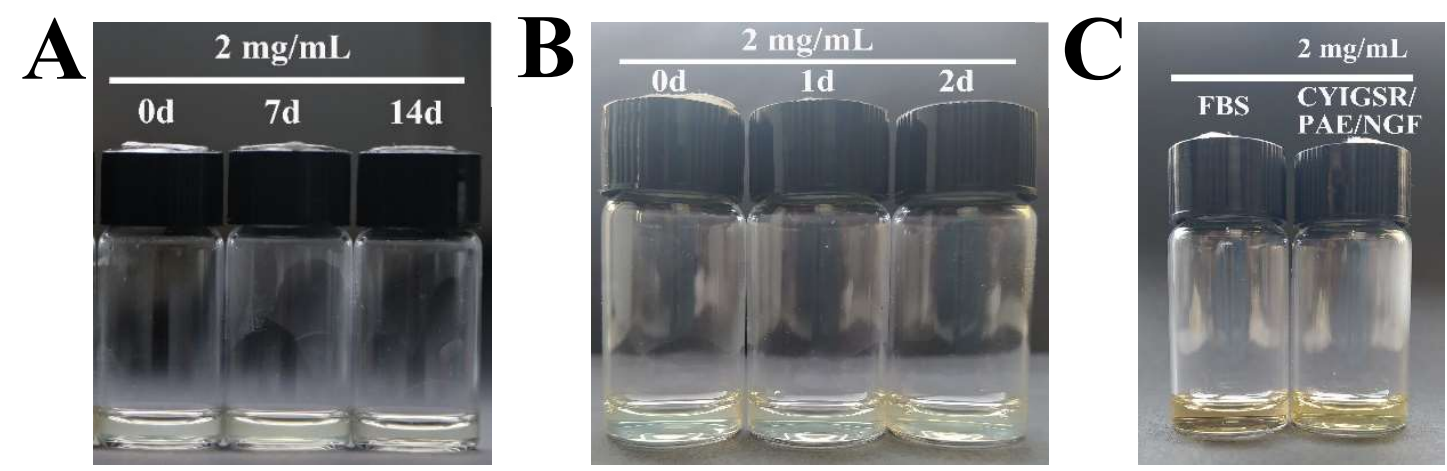

Figure S12 Photographs of CYIGSR/PAE/NGF micelles in PBS (A, 0.01M, pH7.4), fetal bovine serum (FBS) (B, 10\% FBS in PBS) and FBS (C, 100\% FBS) at room temperature. 


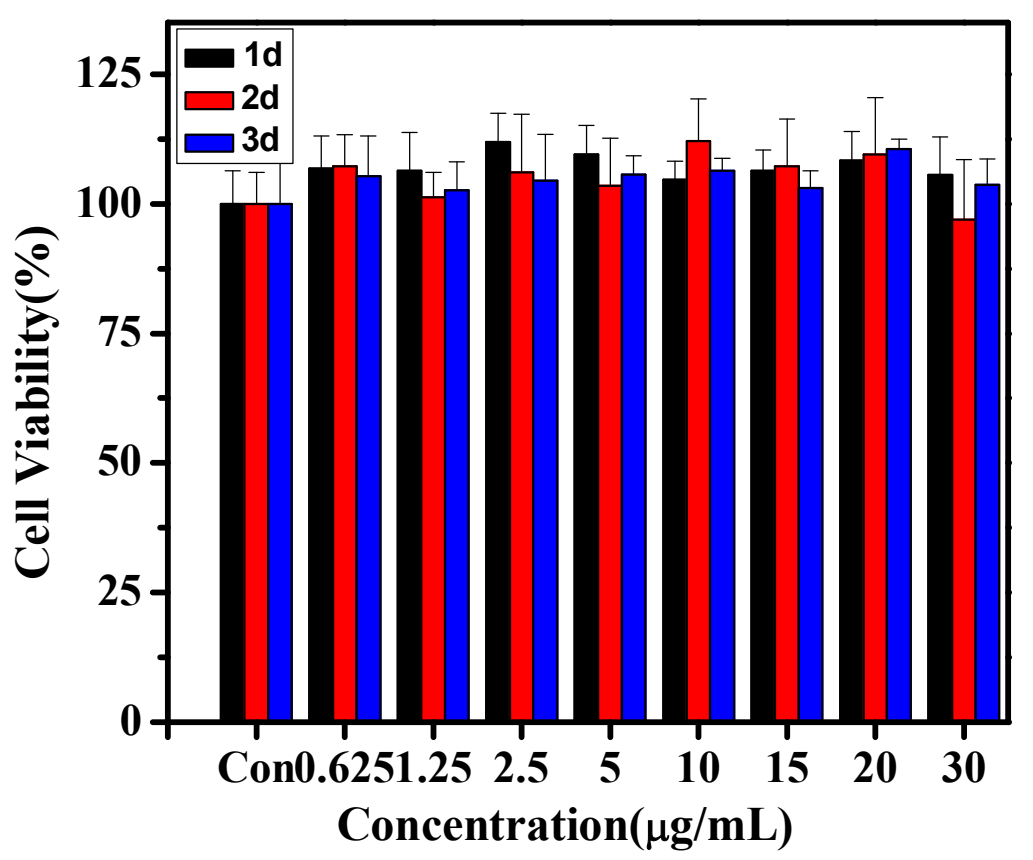

Figure S13 Biocompatibility evaluation of acrylate terminated poly( $\beta$-amino ester $)$ containing alkynyl groups (compound 3) against fibroblast L929. 


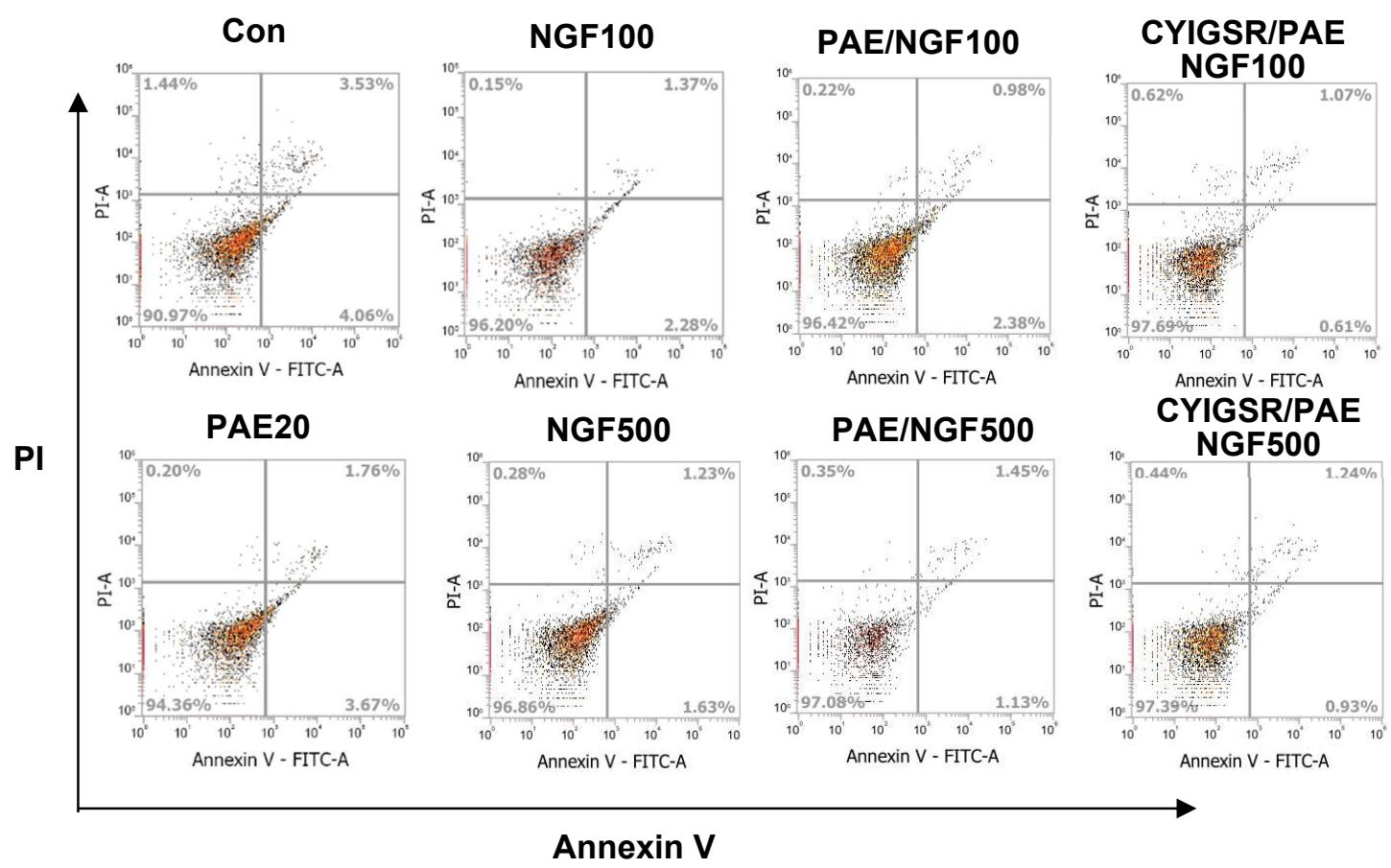

Figure S14 Representative flow cytometry assay images of control (Con), PAE (20 $\mu \mathrm{g} / \mathrm{mL})$, NGF (100 ng/mL), PAE/NGF (100 ng/mL), CYIGSR/PAE/NGF (100 ng/mL), NGF (500 ng/mL), PAE/NGF (500 ng/mL) and CYIGSR/PAE/NGF (500 ng/mL). 


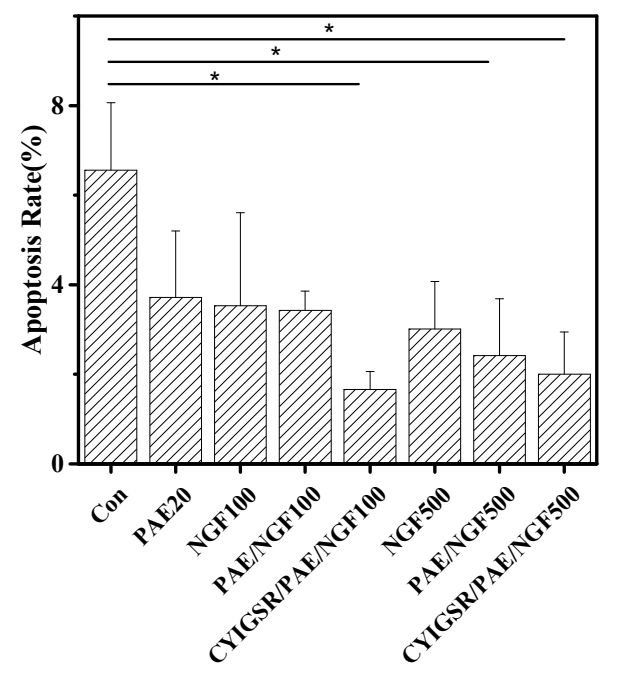

Figure S15 Apoptotic ratio of control (Con), PAE (20 $\mu \mathrm{g} / \mathrm{mL})$, NGF (100 ng/mL), PAE/NGF (100 ng/mL), CYIGSR/PAE/NGF (100 ng/mL), NGF (500 ng/mL), PAE/NGF (500 ng/mL), CYIGSR/PAE/NGF (500 ng/mL). $* P<0.05$. 


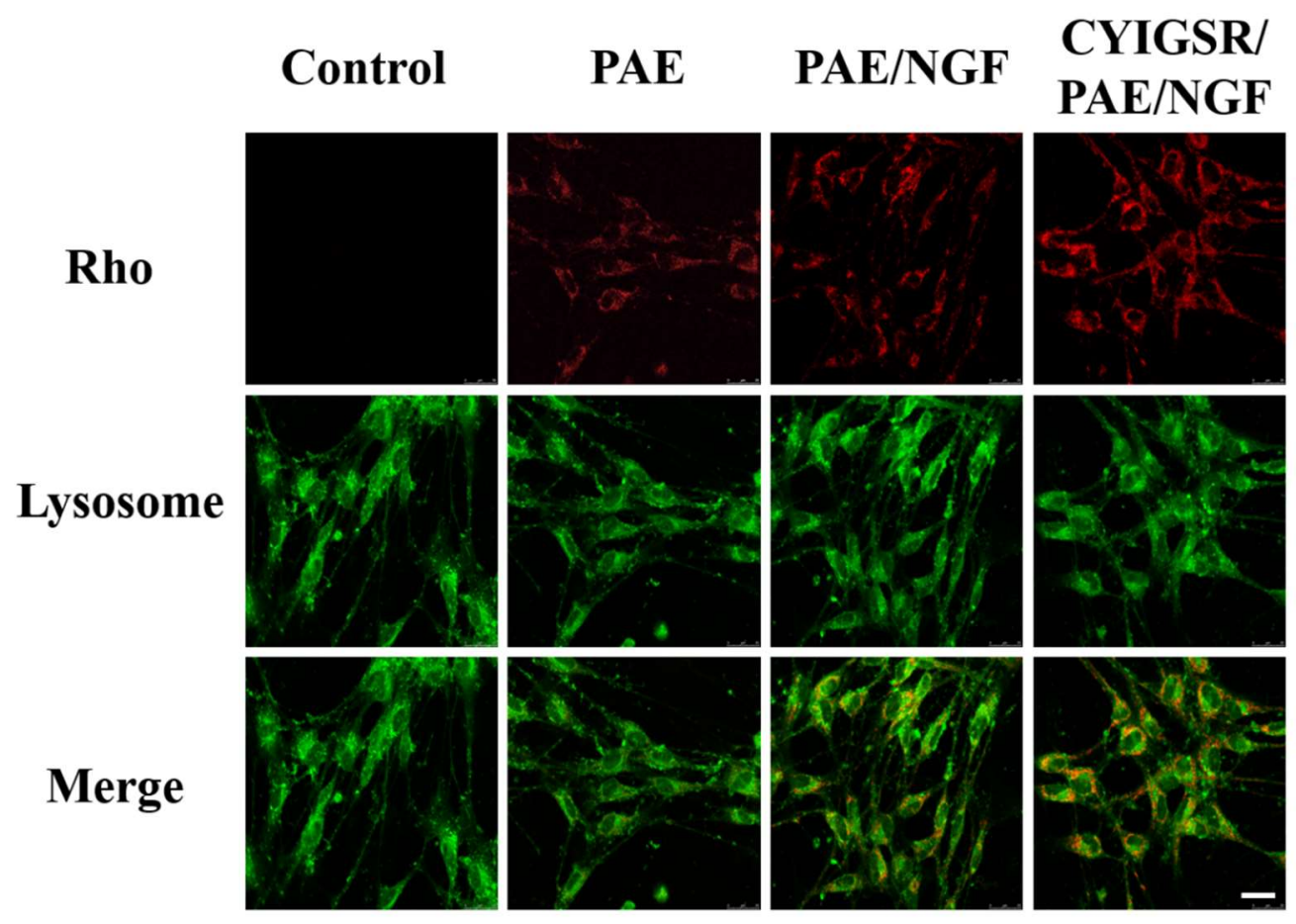

Figure S16 Fluorescent distributions images of CYIGSR/PAE/NGF, PAE/NGF, and PAE for $4 \mathrm{~h}$ (lysosome labeled with lyso-tracker Green, PAE labeled with azidecontaining Rhodamine, the scale bar represents $25 \mu \mathrm{m})$. 
A

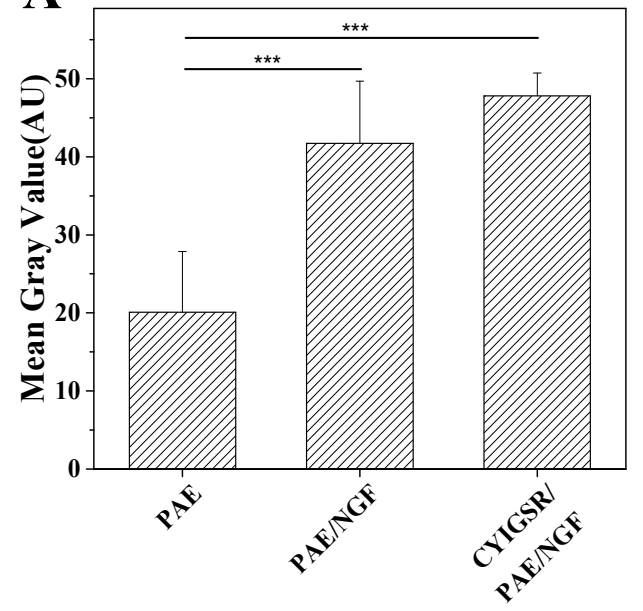

B

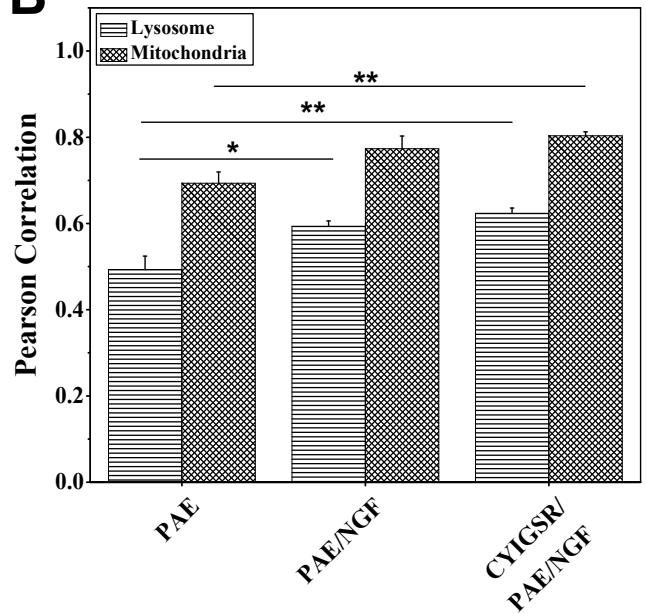

Figure S17 (A) Mean fluorescent intensity of PAE, PAE/NGF and CYIGSR/PAE/NGF; (B) Co-localization degree analyzed by Pearson's correlation coefficient between PAE and mitochondria/lysosome. ${ }^{*} P<0.05, * * P<0.01$ and $* * * P<0.001$. 

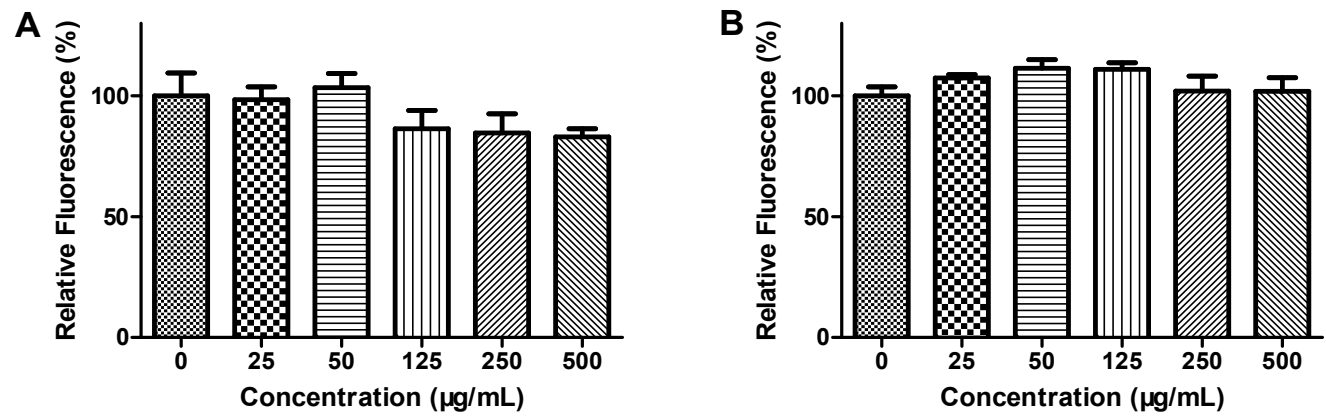

Figure S18 Competitive binding assay of CYIGSR/PAE/NGF micelles and free CYIGSR (A) or NGF (B) peptide. The relative fluorescence was expressed as fluorescence treated with free peptide $(25-500 \mu \mathrm{g} / \mathrm{mL})$ relative to fluorescence without free peptide $(0 \mu \mathrm{g} / \mathrm{mL})$. There was no significant difference between them $(P>0.05)$. 


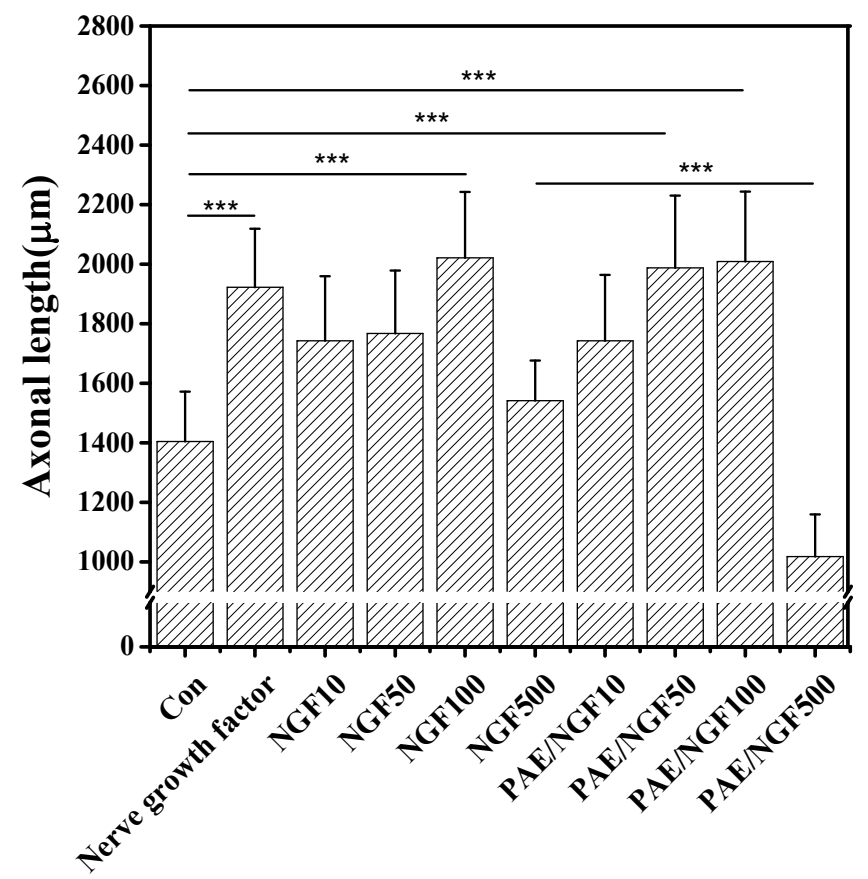

Figure S19 Axonal length of DRG incubated with Control, nerve growth factor, NGF peptide and PAE/NGF. $* * * P<0.001$. 


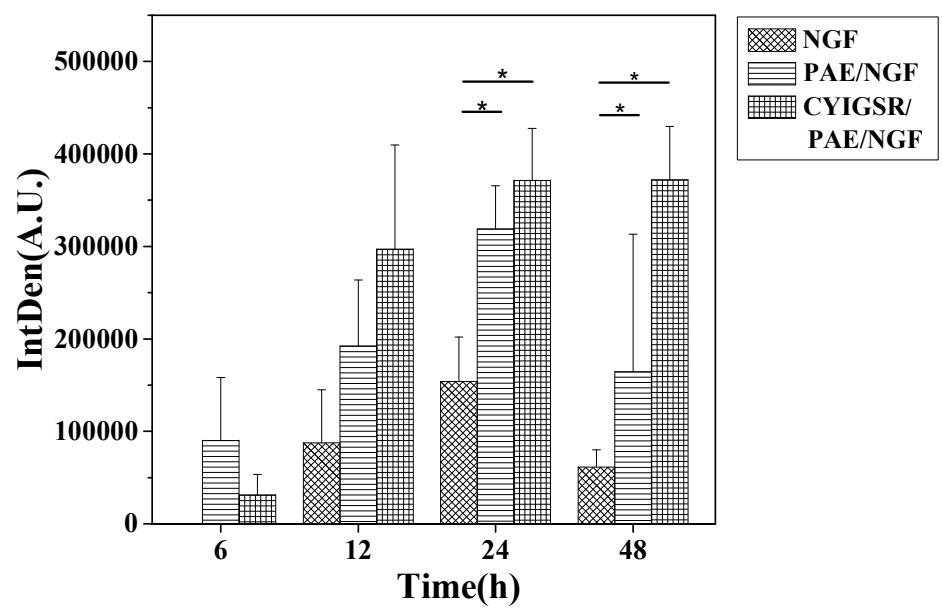

Figure S20 Fluorescence intensities of NIR-labeled CYIGSR/PAE/NGF, PAE/NGF and NGF peptide in injured brain after intravenous injection. ${ }^{*} P<0.05$. 

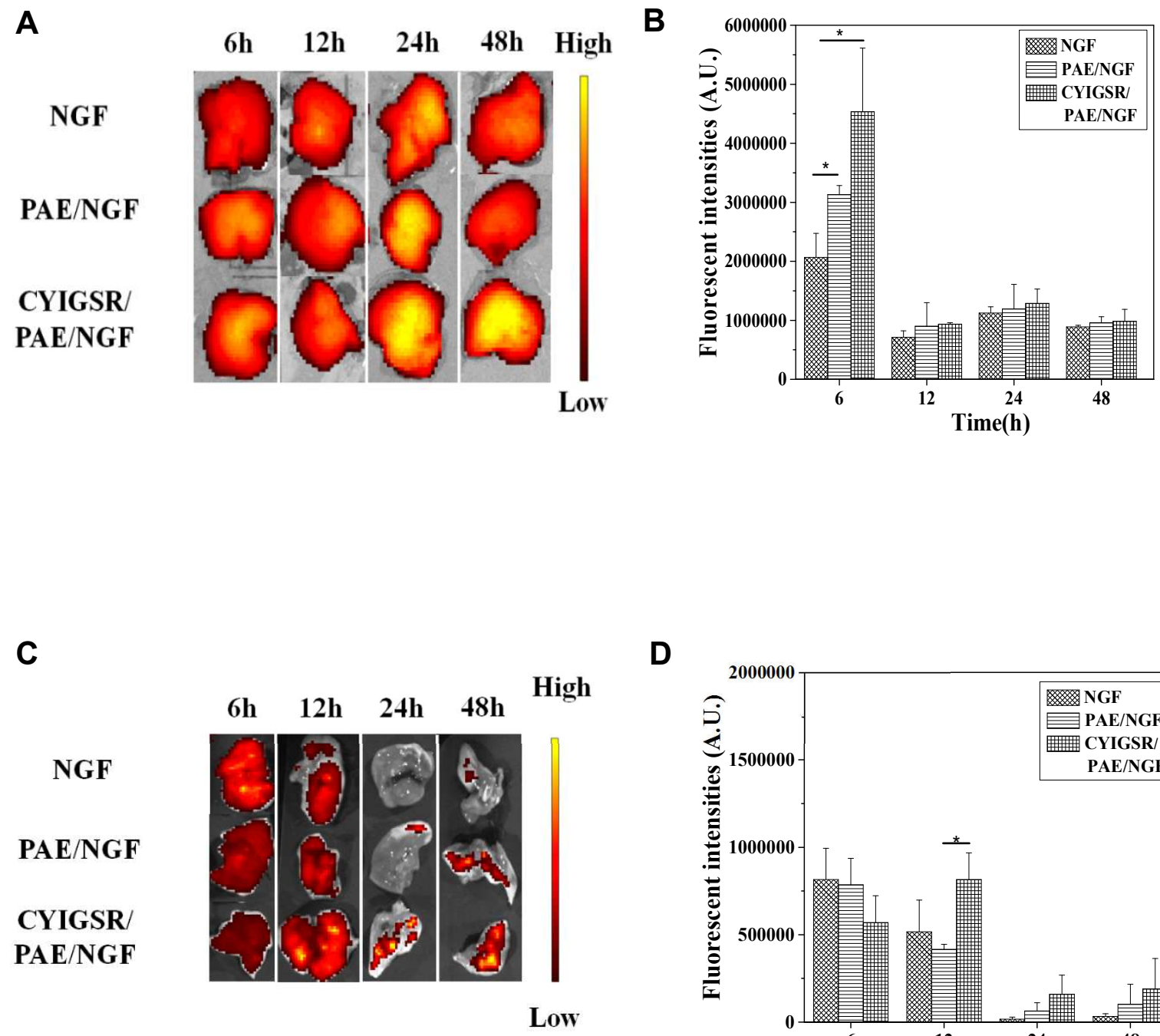

D

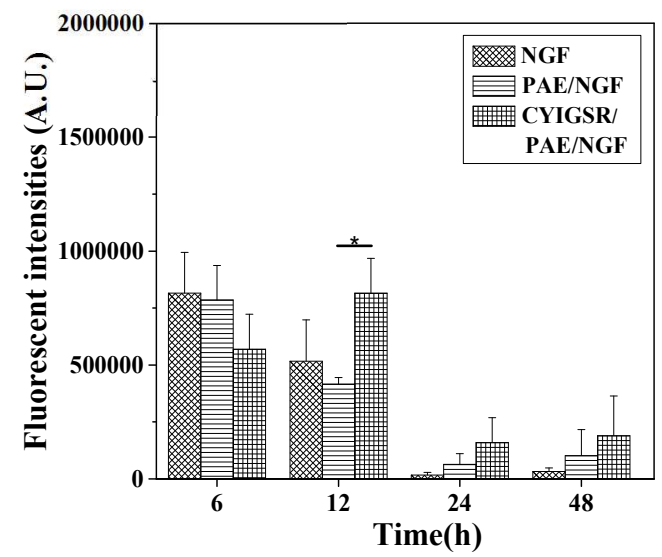

E 6h 12h 24h48h High

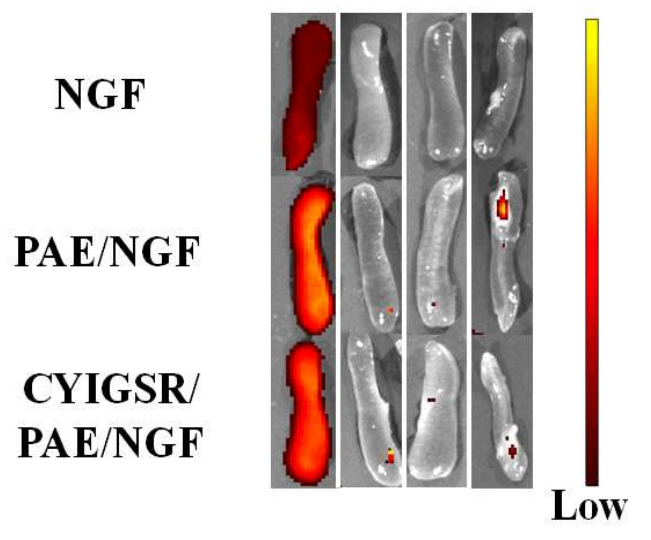

F

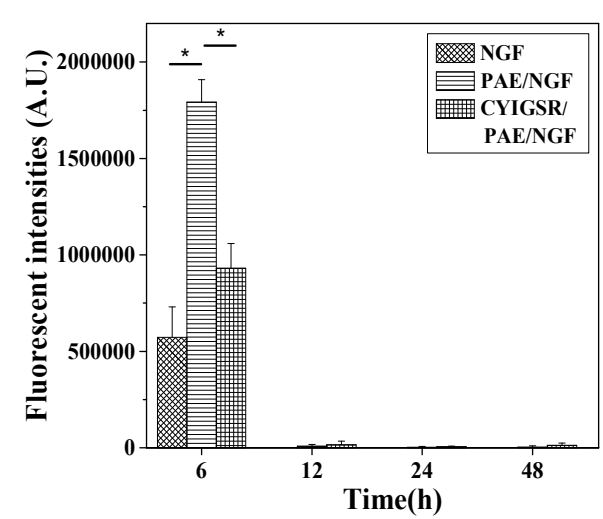


G

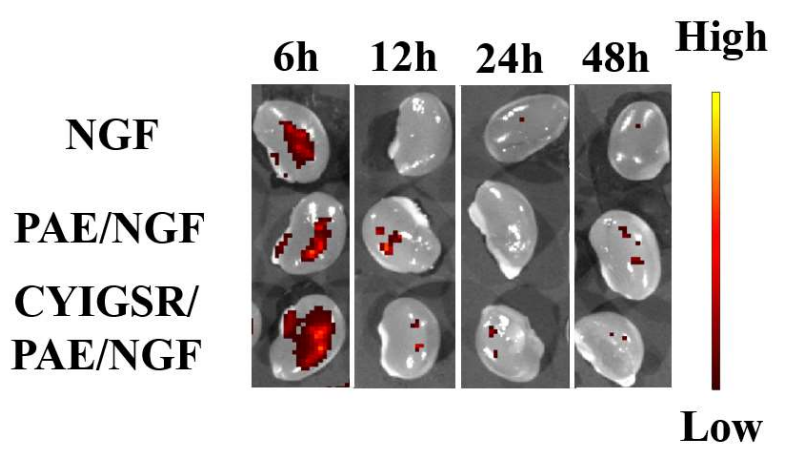

H

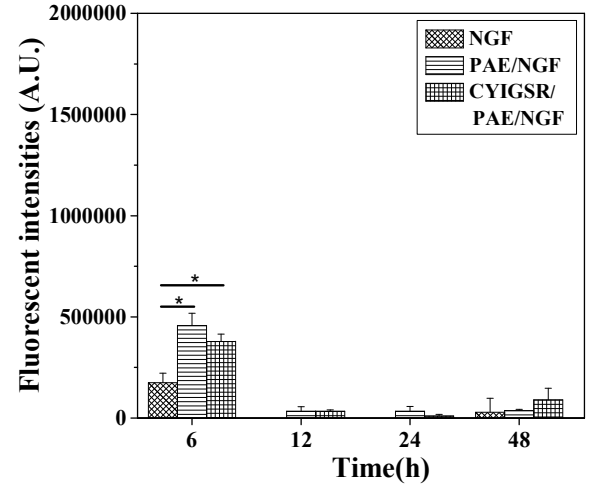

$\mathbf{J}$

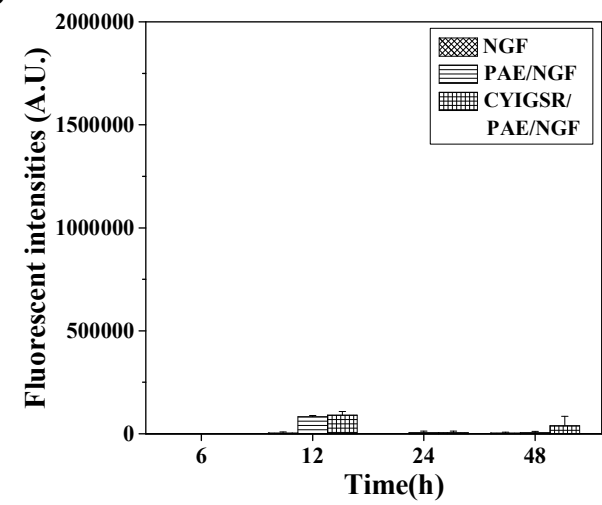

Figure S21 Ex vivo fluorescent images and intensities of CYIGSR/PAE/NGF, PAE/NGF and NGF peptide in major organs. A-B, Liver; C-D, Lung; E-F, Spleen; GH, Kidney; I-J, Heart. * $P<0.05$. 


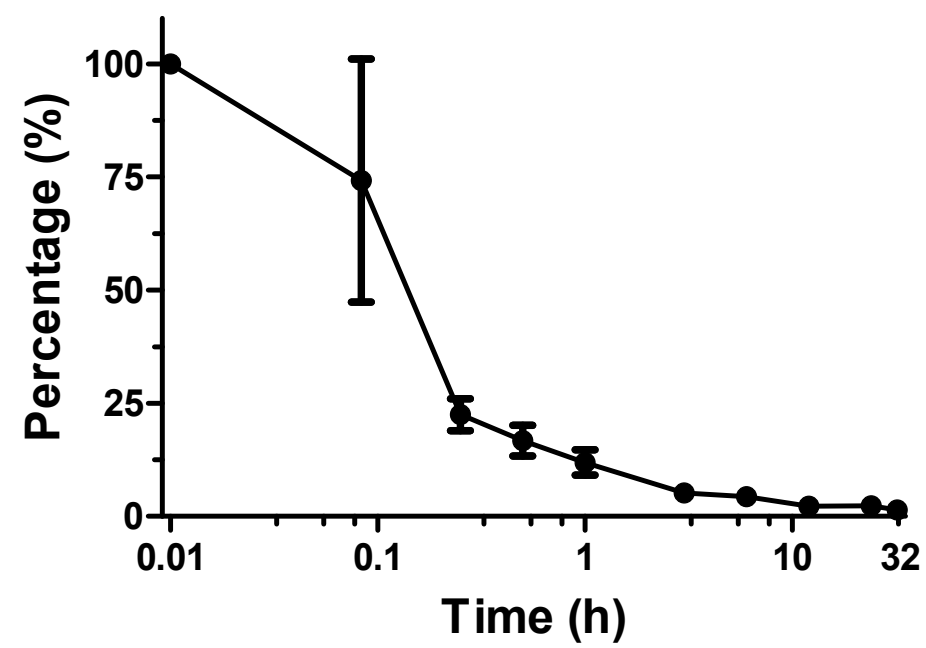

Figure S22 Pharmacokinetics of CYIGSR/PAE/NGF in healthy mice. 


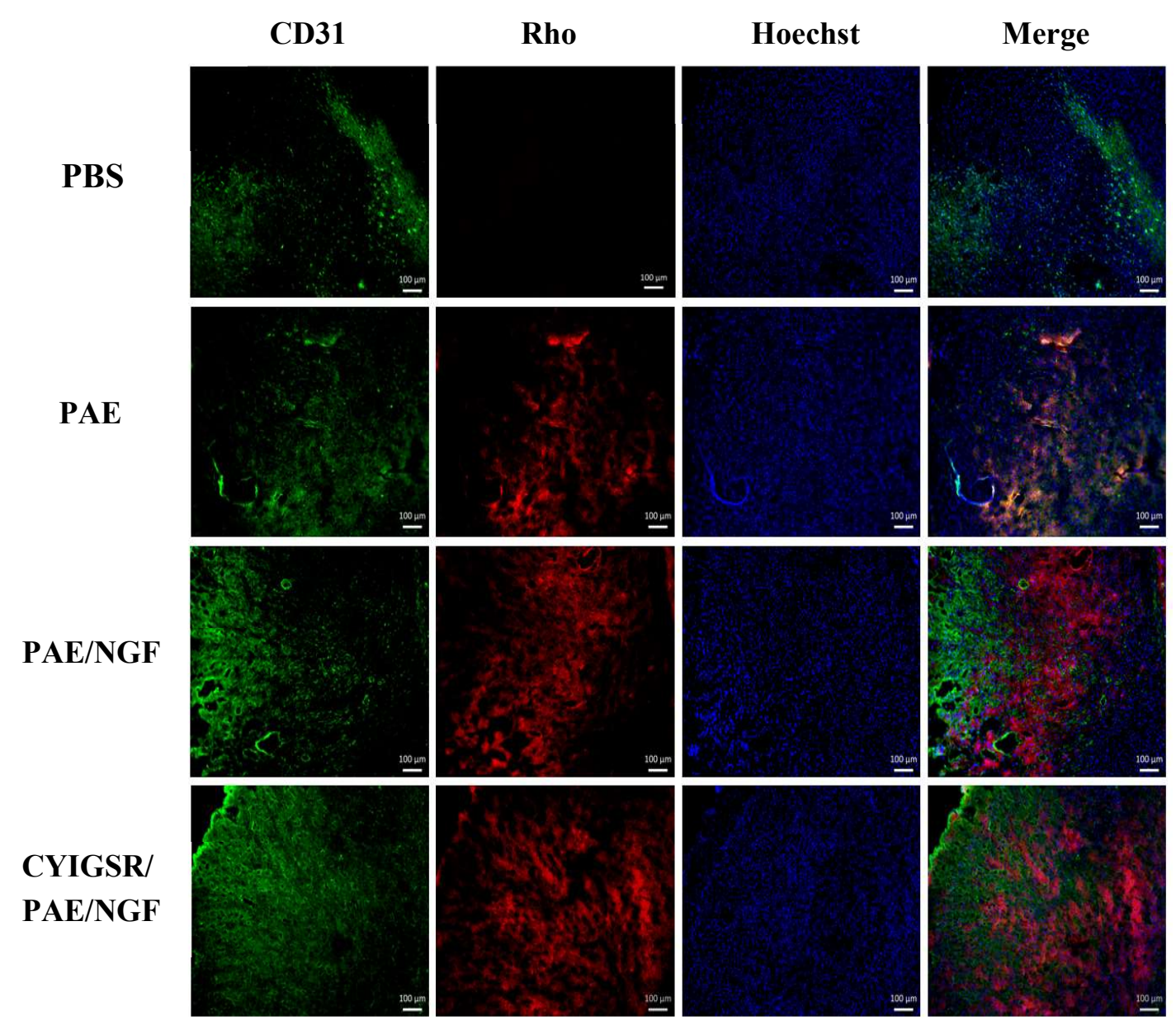

Figure S23 Brain penetration behaviors after $6 \mathrm{~h}$ tail vein injection of CYIGSR/PAE/NGF, PAE/NGF, PAE and saline. Blood vessels were stained with CD31 (Green), CYIGSR/PAE/NGF, PAE/NGF, PAE were labelled with Rhodamine-PEG-N 3 (Red), the nuclei were stained by Hoechst (Blue). 
Normal
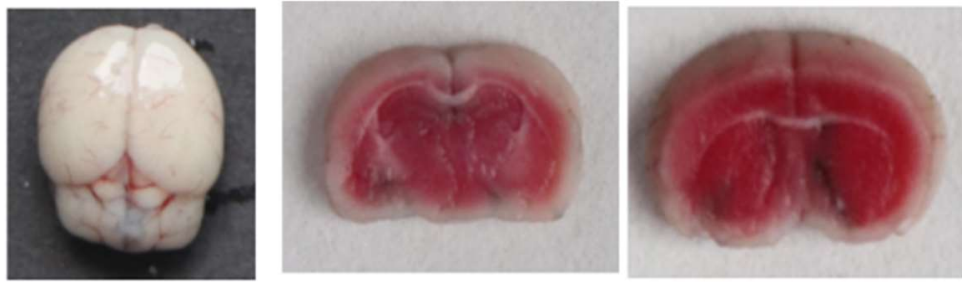

Figure S24 Evans blue extravasation and TTC staining of normal brain. 

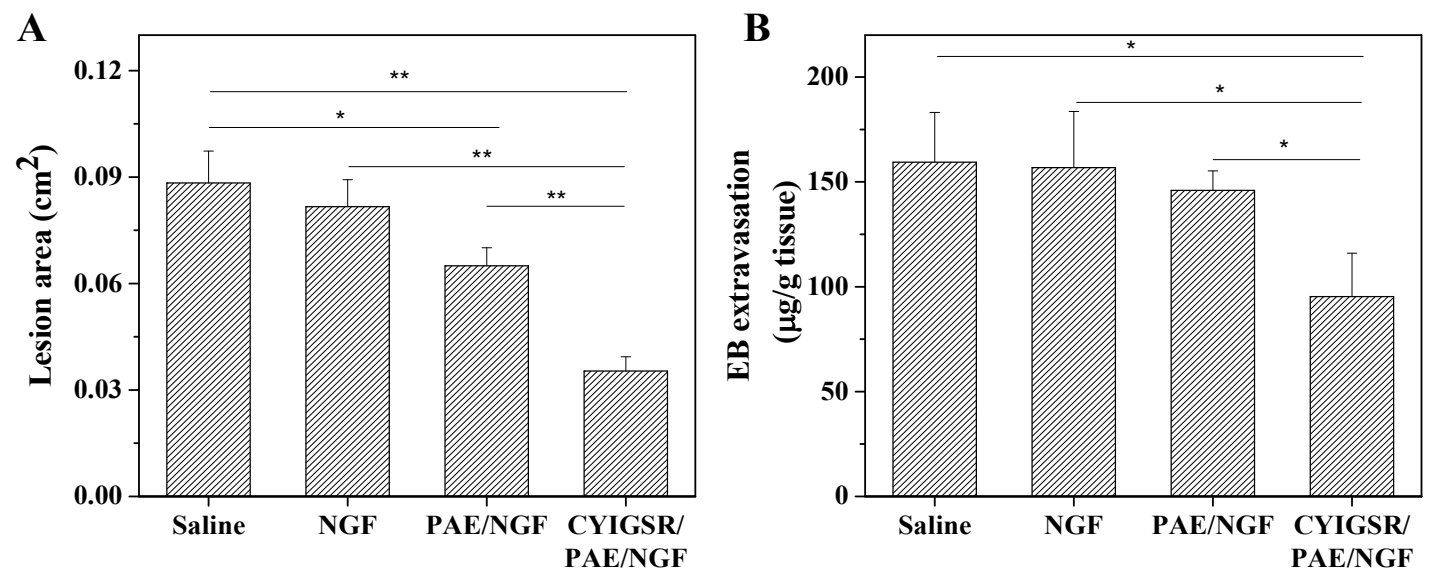

Figure S25 Lesion areas (A) and Evans blue concentration (B) after 8 days treatment $\left({ }^{*} P<0.05,{ }^{* *} P<0.01\right)$. 
GFAP
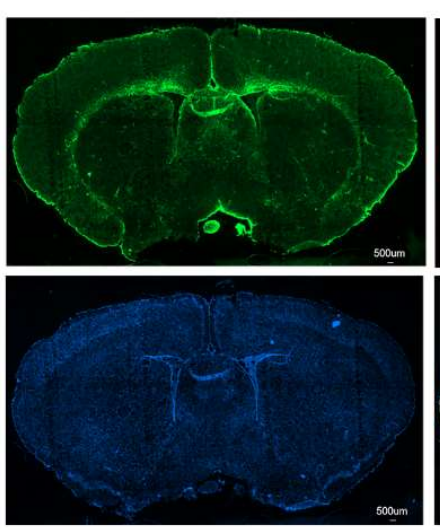

Hoechst
$\beta$-Tubulin
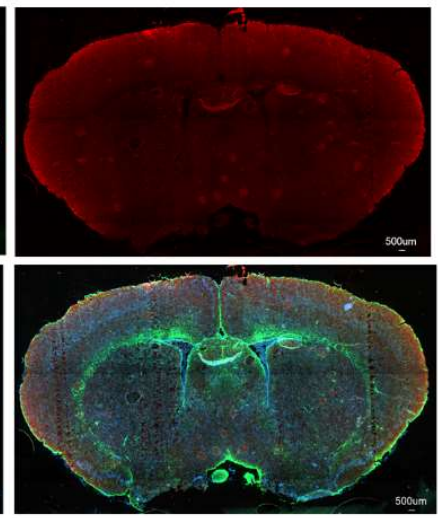

Merge

Figure S26 GFAP and $\beta$-tubulin III immunofluorescence staining of normal brain. 


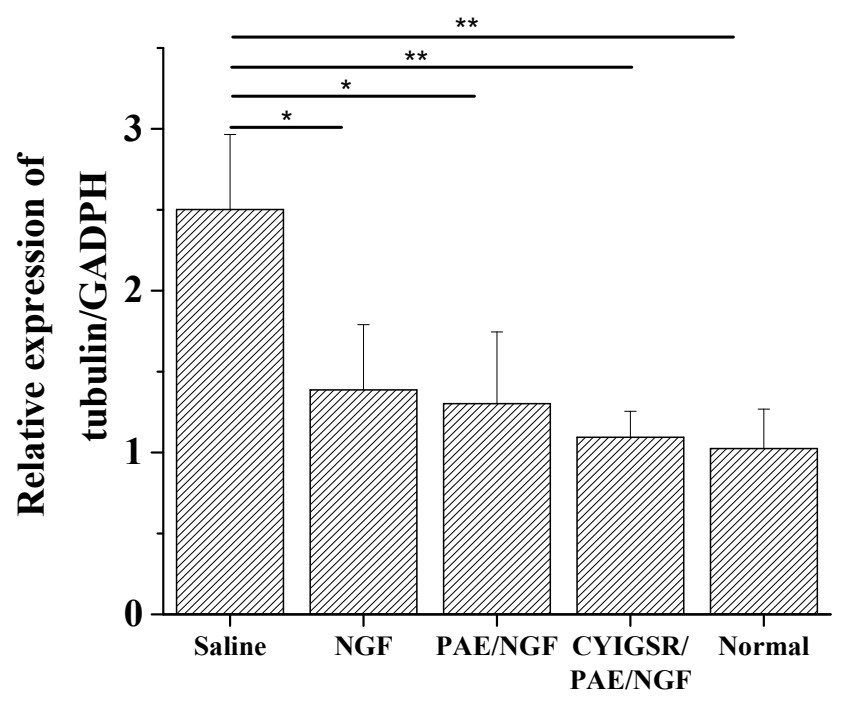

Figure S27 Relative expression of $\beta$-tubulin gene in injured brain tissue treated with Saline, NGF, PAE/NGF and CYIGSR/PAE/NGF $(* P<0.05, * * P<0.01)$. 